\title{
Expressing the GIVE event in Papuan languages: A preliminary survey
}

\author{
GER REESINK
}

\begin{abstract}
The linguistic expression of the GIVE event is investigated in a sample of 72 Papuan languages, 33 belonging to the Trans New Guinea family, 39 of various non-TNG lineages. Irrespective of the verbal template (prefix, suffix, or no indexation of undergoer), in the majority of languages the recipient is marked as the direct object of a monotransitive verb, which sometimes involves stem suppletion for the recipient. While a few languages allow verbal affixation for all three arguments, a number of languages challenge the universal claim that the 'give' verb always has three arguments.
\end{abstract}

Keywords: affix order, alignment, argument structure, cross-reference, ditransitive, object, Papua New Guinea, perspective, serial verb, suppletion, syntax, transitivity, word order

\section{Introduction}

\subsection{Essai sur le don}

Given the nature of humans as a social species, one of the most basic events in our cultures involves the exchange of goods. This event involves a GIVER, a GIFT, and a RECIPIENT. Newman (1996) has argued that the verb 'give' is therefore a basic verb, illustrated by a plethora of morphosyntactic constructions that are available crosslinguistically. In Newman (2002) he shows how in some languages a direct link can be drawn between cultural values and practices on the one hand and the linguistic expression of the GIVE event on the other hand. For example, in Dyirbal, position, movement, and kinship obligation are important factors determining lexical stems; in Japanese relative status of giver and recipient determine whether the giving is 'upwards' or 'downwards'; and in Chipewyan, the verbs for 'take' and 'give' change their morphological properties according to shape and consistency of the thing transferred and the (lack 
of) control of the actor. On the other hand, Maori is cited as a language in which 'give' has incorporated directional verbs specifying 'hither' or 'thither', without any clear cultural correlates.

In this article I present an overview of GIVE constructions as found in 72 Papuan languages; see below for classification and geographic distribution. Since my first encounter with Papuan cultures in the 1970s I have been struck by the social importance of keeping track of debts in order to reciprocate in an adequate manner. I also realized that "keeping scores" is not at all peculiar to Papuan cultures. There seems to be a universal human propensity to maintain social relations in harmonic balance. Verbs translatable as 'reciprocate', 'give in return', or 'pay back' are widespread in these languages and suggest a social preoccupation, illustrated by their Tok Pisin equivalent bekim or pe bek. However, I will not discuss crosslinguistic realizations of this concept or possible other verbs that denote certain aspects of the GIVE domain, such as 'donate', 'present', 'send', simply because most descriptive sources do not provide adequate information. The basic verb translated as 'give', however, can be found in almost all grammatical descriptions, and this provides enough interesting material to warrant a typological overview.

\subsection{Alignment}

Whereas there appears a (universal) cognitive preference to assign the subject role in active voice to the giver (Newman 2002: 80), languages differ with respect to the syntactic roles assigned to the gift or the recipient. Blansitt (1979, 1984: 129) coined the term "dechticaetiative"1 for languages in which the bitransitive recipient or beneficiary has the same formal marking and/or formal relations as the monotransitive object, in contrast with "dative" languages in which the bitransitive GIFT is formally like the monotransitive object. Dryer (1986) uses the terms "Primary Object languages" and "Direct Object languages" to refer to the same distinction.

Haspelmath (2005) makes a finer distinction by recognizing three different alignments, as shown in Figure 1, taken from Haspelmath (2005: 2). His "indirective alignment" (a), in which the gift $($ Theme $=\mathrm{T}$ ) is marked as the Patient $(\mathrm{P})$ of a monotransitive construction, agrees with Blansitt's "dative" and Dryer's "direct object" type. There are two alignments in which the Recipient (R) of a bitransitive receives the same formal marking as the object $(\mathrm{P})$ of a monotransitive predicate. In the "neutral" alignment (b) this holds also for the gift (T), so there is no special marking for monotransitive $\mathrm{P}$, or bitransitive $\mathrm{T}$ or

\footnotetext{
1. Blansitt (1984: 148) explains that this term is based on the Greek terms for 'receive' and 'accusative' to capture the notion of 'recipient-as-accusative'. It is not surprising that this neologism has not caught on.
} 


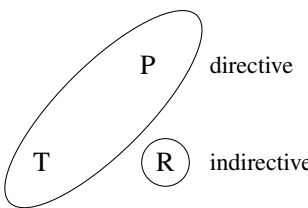

Indirective alignment

(a)

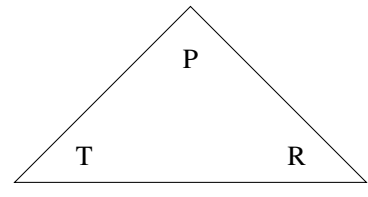

Neutral alignment

(b)

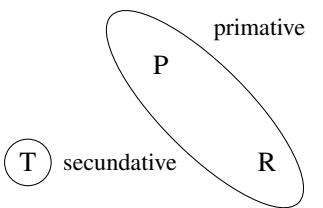

Secundative alignment

(c)

Figure 1. Alignments for recipient and gift (after Haspelmath 2005)

R. In the "secundative" alignment (c), not only are R and P treated the same, hence named "primative", but in addition the gift is marked differently, named "secundative".

In languages like English and Dutch, as well as many other European languages, speakers have a choice when using the 'give' verb: the recipient may be separately marked from $\mathrm{P}$ in monotransitive and $\mathrm{T}$ in ditransitive constructions (indirective), or both recipient and theme are marked as $\mathrm{P}$ in a monotransitive construction (neutral). In neither Dutch nor English is a truly secundative alignment possible, although the English verb present allows all three alignments, although the neutral alignment is not acceptable to some native speakers:
a. Indirective: I presented the trophy to her.
b. Neutral: I presented her a trophy.
c. Secundative: I presented her with a trophy.

Newman (2002: 91) focuses on cultural and cognitive factors relevant to the expression of the GIVE event. Employing the terminology from Tuggy (1998), he correlates the HUMAN INTERACTION perspective with the recipient as direct object of a monotransitive predicate, while the OBJECT MANIPULATION perspective correlates with the gift as direct object. Both a neutral and secundative alignment would qualify as the Human Interaction perspective. While some languages allow a choice between these perspectives, others choose one over the other, although it is difficult to identify some cultural or social basis for these choices.

My aim in this article is to chart the distribution of morphosyntactic constructions that show either the Human Interaction or Object Manipulation perspective. In other words, I want to determine whether the recipient of the 'give' verb can be or has to be expressed as the direct object of a monotransitive verb. ${ }^{2}$

2. Borg \& Comrie (1984: 123) show for Maltese that both the gift and the recipient may have all or just some of the properties of a prototypical direct object. They conclude that 'give' is syntactically a very atypical ditransitive verb and warn that the most typical ditransitive 
This will demonstrate which languages exhibit suppletion for the recipient. It seems important to correlate the expression of the GIVE event with direct object marking on monotransitive verbs and with the way the role of beneficiary can be expressed.

The tables given in the Appendix show for each language (i) the word order in the clause; (ii) whether the verb has prefix, a suffix, or neither to index a direct object; (iii) whether the recipient receives the same marking as a monotransitive object (P in Figure 1); (iv) which perspective is used for a GIVE event; (v) whether the verb stem is suppletive for the recipient; and (vi) whether the beneficiary can be marked on the verb. ${ }^{3}$

The article is structured as follows: first, because it is well known that the term "Papuan" does not imply any genealogical entity, I will devote some discussion to the putative affiliations of languages in my sample in Section 2.

In Section 3 I provide examples that illustrate the Human Interaction perspective (either neutral or secundative alignment) according to their different verbal affixation patterns. Section 4 is devoted to languages that allow a choice between the two main alignments: the Human Interaction and Object Manipulation perspectives, as well as the few languages that have Object Manipulation as the only perspective. In Section 5 I discuss the languages that realize the $\mathrm{Hu}-$ man Interaction perspective by stem suppletion for the recipient. In Section 6 I present some typologically unusual patterns in which a few scattered languages allow three arguments indexed on the verb. In Section 7 data are presented that contradict some universal claims for 'give' predicates. In Section 8 I show how the expression of the beneficiary in many languages is related to the 'give' construction. Section 9 contains my conclusions, representing a sample of not more than $9 \%$ of all Papuan languages.

\section{Classification of Papuan languages in the sample}

There have been several decades of extensive scepticism among Papuanists regarding the proposal of one large family, first known as the Trans New Guinea phylum (McElhanon \& Voorhoeve 1970, Wurm (ed.) 1975). In addition a number of smaller families, ten according to Wurm, more than sixty on a conservative count according to Foley (1986: 213, 275), plus a number of isolates have been proposed. However, the most promising grouping of Papuan languages is that proposed by Ross (2005). By comparing and reconstructing sets

verb in a language may not be 'give', so that such research requires cross-checking with other verbs of similar valency. For quite a number of languages in my sample the sources consulted have no examples of other ditransitive verbs or even explicitly deny their existence. Hence, my aim is rather modest: simply charting whether or not recipients are expressed as DO of monotransitive verbs in a particular language.

3. The actual data for each language can be found in the Supplementary Online Materials. 


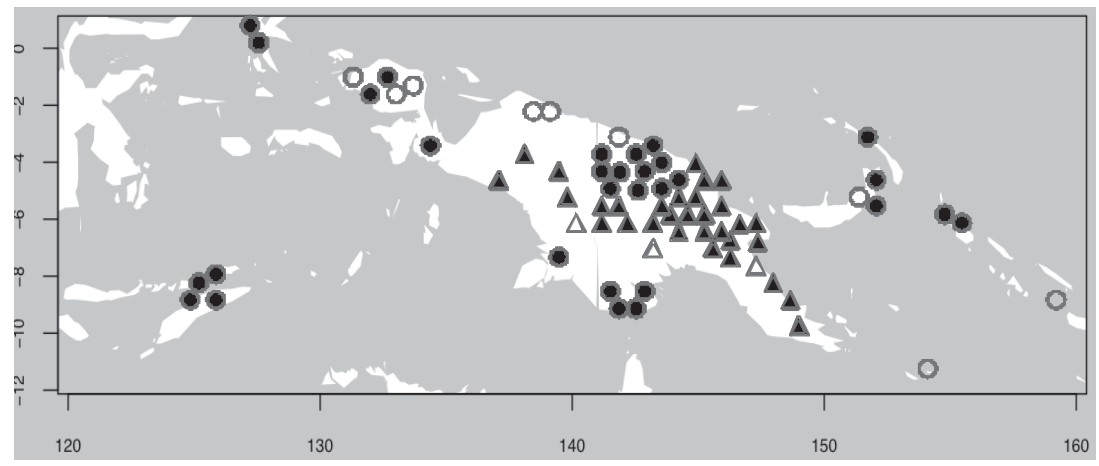

Map 1. Map of 72 Papuan languages with alignments (triangles represent 33 TNG languages and circles 39 non-TNG; solid = Human Interaction required or possible; empty = only Object Manipulation)

of pronominal forms, Ross has given some diagnostic evidence for a major Trans New Guinea (TNG) family, although not exactly congruent with Wurm's original proposal and his 22 smaller non-TNG families and some isolates. Ross (2005: 49) warns explicitly that his classification is no more than a first step of a rigorous application of the comparative method and needs more thorough comparative work, which may change some preliminary assignments.

In his re-assessment of the TNG hypothesis, Pawley $(2005,2007: 47)$ remarks that a few groups in the south and west of the Papuan expanse are rather marginal members of the newly defined TNG family. These include Kiwai, Marind, and Inanwatan along the south coast and the languages of Timor, Alor, and Pantar in the islands to the west of Papua New Guinea. It is these languages in the sample investigated in Reesink et al. (2009) that do not cluster with the rest of TNG. For this reason I will discuss them as non-TNG languages. The tables in the Appendix list the languages of this typological overview alphabetically, divided into 33 TNG and 39 non-TNG languages. Pragmatically, this dichotomy is simply a tool to distinguish two main types of Papuan languages. Although I am fairly confident that the TNG family forms a genealogical unity on the basis of the largely congruent results from Ross (2005) and Reesink et al. (2009), more rigorous comparative evidence is needed to make this a solid scientific claim. The grouping of the non-TNG languages is internally far more heterogeneous. So far, I do not see good reasons to split my sample of 39 non-TNG languages into different families, although in the individual sketches given in the Supplementary Online Materials their postulated lower level affiliations are mentioned. 


\section{Human Interaction perspective}

\subsection{A Papuan preference}

All languages belonging to the TNG family have SOV as their basic order, and all have $S$ or A marked by a verbal suffix, often in a portmanteau with tenseaspect-mood (TAM) categories. Of my sample of 33 TNG languages, ten do not have any affixal marking for direct object on a monotransitive verb, fifteen mark the direct object by a prefix, and thirteen do so by means of suffix. (Note that the totals do not add up because a number of languages have both object prefixation and suffixation depending on verb class.) Of the 39 non-TNG languages, the proportions are similar: thirteen have no verbal indexing for direct object, sixteen have a prefix, and fifteen a suffix. Again, a few languages have both prefixes and suffixes, depending on the verb class or person or number categories.

As seen in Map 1, the great majority of these Papuan languages (28 out of 33 TNG and 29 out of 39 non-TNG) mark the recipient of the 'give' verb as the direct object of a monotransitive verb. The Human Interaction perspective seems to be the preferred option for Papuan languages. This means that in all Human Interaction languages the predicate has two object constituents that are marked as the Do of a monotransitive verb, the recipient being the primary object, and the gift being the secondary object. If a language has an object affix on the verb, it indexes the primary object. Only one language, Mali (Section 4.3) has a true secundative alignment in that the gift is clearly differently marked from the $\mathrm{P}$ of the monotransitive and the $\mathrm{R}$ of the ditransitive ((c) in Figure 1).

As indicated in the tables in the Appendix, only three TNG languages do not exhibit the preferred Human Interaction alignment, but have Object Manipulation as the only option. Four TNG languages have a choice between the Human Interaction and Object Manipulation perspectives. Two languages, both of the Ok family (Mian and Telefol), allow no choice, but index both the gift and recipient on the verb. These latter languages will be discussed in Section 6, together with two non-TNG languages that share the unusual indexing of three arguments.

In the next section I will give examples of languages that have the Human Interaction perspective as the only option, representing each of the morphological verbal templates: direct object as prefix, as suffix and without affixation of DO. Section 3.2 illustrates this for three TNG languages, and Section 3.3 for non-TNG languages that occur with the same verbal templates.

\subsection{Human Interaction perspective as only option in TNG}

This section illustrates three TNG languages with different verbal morphological templates: Menya marks the object by a verbal prefix, Kamoro has a verbal suffix, and Golin lacks verbal affixation for the object. 
Menya (Whitehead 2004: 23-25), a member of the Angan family, marks the recipient of 'give', 'show/teach', 'tell (a story)' obligatorily as the primary object by the object prefix. The stem tap 'give' is used for 1st and 2nd person recipients, as in (2a); for 3rd person recipients the verb $i$ 'do' is used. The object prefix for 1 st person dual is the same as the one in a monotransitive verb, as in (2b).

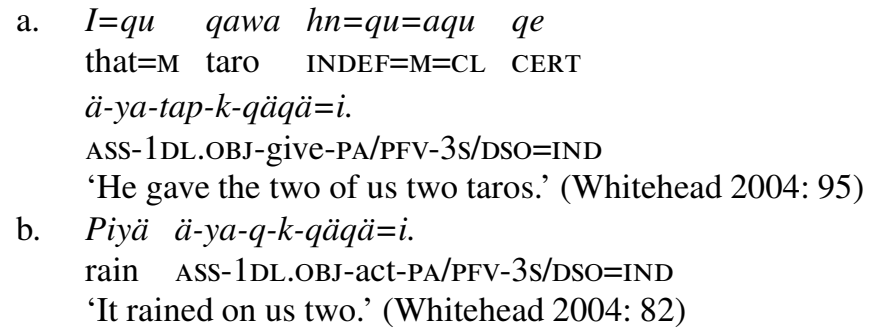

The order of suffixes in Kamoro of the Asmat-Kamoro family (Ross 2000: 137 ) is [V-U-A], also on the verb kemě 'give', which according to Drabbe (1953: 15 ) is a compound of the stems ké and mě. Object and subject suffixes (Drabbe 1953: 10-11) are given in Table 1. There are very few verbs that can be inflected and also occur as autonomous verbs. Most verbs (Drabbe 1953: 38) make use of "light verbs" (Drabbe calls them primaire hulpwerkwoorden), such as $k \check{e}-r$ 'hold in hand', $k \check{e}-r$ 'act' (these verbs are given as two homophonous verbs), $i-r$ 'be; say', $m \check{e}-k$ 'cause'. This analysis suggests that 'give' combines 'hold' and 'cause'. In various inflected forms verbs require a lexically determined ligature, either $-r$ - or $-k$-, between the stem and tense markers.

Table 1. Object and subject suffixes in Kamoro

\begin{tabular}{lll}
\hline & OBJECT & SUBJECT \\
\hline $1 \mathrm{SG}$ & $-n-$ & $-i$ \\
$2 \mathrm{SG}$ & $-n-$ & - ém/-am \\
3SG & $-r-/ 0$ & $-\check{e} /-a o$ \\
& & \\
$1 \mathrm{PL}$ & $-n-$ & $-o m$ \\
2PL & $-n-$ & $-i m i /-t i m$ \\
3PL & $-r-/ 0$ & - til-atě \\
& & $-(u) m u$ \\
$1 \mathrm{DU}$ & & - imìmi \\
2DU & & $-\grave{i m u t i /-a ̀ m u t i ~}$ \\
3DU & &
\end{tabular}


Comparison of (3a) and (3b) shows that the recipient is marked by the regular object suffix $-n$ 'NON3' used on monotransitive verbs.

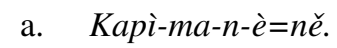

follow-PRES-NON3.OBJ-3SG.SUBJ=NEG

'He does not follow me.' (Drabbe 1953: 15)

b. A-kemě-k-ajmi-n-i.

FUT-give-LIG-FUT-NON3.OBJ-1SG.SUBJ

'I will give you.' (Drabbe 1953: 19)

Golin (Bunn 1974, Evans et al. (eds.) 2005) and Salt-Yui (Irwin 1974) of the Chimbu family lack verbal affixation for arguments other than agent/subject. In ditransitive clauses, the order is typically [S-Theme Object-Recipient/Goal Object-Verb] with both objects unmarked, as shown in (4a) and (4b) for Golin. It so happens that both examples have the ASSERTIVE morpheme $/ \mathrm{g} / \mathrm{which}$ conditions the 1sG suffix $i \sim l$ to be realized as a zero morph (Evans et al. (eds.) 2005: 42).

$$
\begin{aligned}
& \text { a. Na bolma kama i te- } \varnothing \text { - } g \text { - } a \text {. } \\
& \text { 1sG pig black 2SG give-1sG-ASS-PROX } \\
& \text { 'I give you a black pig.' (Evans et al. (eds.) 2005: 94) } \\
& \text { b. } N a \text { buke gal gili- } \emptyset \text { - } g \text {-e. } \\
& \text { 1sG book bag put-1sG-ASS-PROX } \\
& \text { 'I put the books in my bag.' (Evans et al. (eds.) 2005: 94) }
\end{aligned}
$$

\subsection{Human Interaction perspective as only option in non-TNG}

In this section the obligatory perspective of Human Interaction is illustrated in three languages, according to their indexing of the DO on the verb: prefixing Gizrra, suffixing Alamblak, and Yessan-Mayo, which has no affixation of arguments on the verb.

Gizrra (the double / $\mathrm{rr} /$ represents a trill in contrast to a single / $\mathrm{r}$ / for a flap) is a member of the Eastern Trans-Fly family (van Bodegraven \& van Bodegraven 2004). In this V-final language the subject is marked by a pormanteau suffix to the verb, indicating also past versus non-past tense. The direct object of transitive verbs is marked by a prefix, giving the verbal morphological structure [U$\mathrm{V}-\mathrm{A}$ (+ TENSE)]. While this argument marking follows a nominative-accusative pattern, the verb stem follows an ergative pattern, in that for some intransitive verbs number of $S$ is marked by suppletion, while for some transitive verbs suppletion marks the number of the object.

In the case of the 'give' verb, it is the gift that is being marked for number by a suppletive stem, while the recipient is indexed by the regular direct object prefix, as shown in (5a) and (5b). Note that the pronominal recipient is flagged by the genitive marker, but indexed as undergoer on the verb, as is also required 
for the animate direct object of a monotransitive verb (see Supplementary Online Materials).

a. Wa kü-rü katam kó-kyan-órr.

3SG.SUBJ 1SG-GEN banana 1sG.OBJ-give.SG-3SG.PAST

'He gave me a banana.' (van Bodegraven \& van Bodegraven 2004: 25)

b. Wa kü-rü katam k(ü)-lión-órr.

3SG.SUBJ 1sG-GEN banana 1sG.OBJ-give.PL-3sG.PAST

'He gave me bananas.' (van Bodegraven \& van Bodegraven 2004:

25)

Alamblak (Bruce 1984) is a member of the Sepik Hill family, belonging to the larger Sepik family (Foley 2005: 127, Ross 2000: 212). This language has SOV as its constituent order and its verb morphology is [V-TENSE-A-U] for transitive verbs. An adjective or quantifier, referring to either the subject or object or both, may be incorporated by suffixation to the verb stem (Bruce 1984: 174), as buga 'all' in (6).

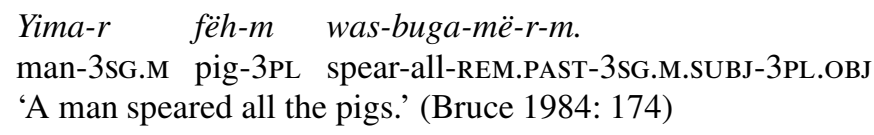

In the case of a ditranstive verb like hay 'give' the recipient is crossreferenced by the object suffix on the verb, and the quantifier buga 'all' can refer to just the gift, or both the gift and recipient (Bruce 1984: 174-175):

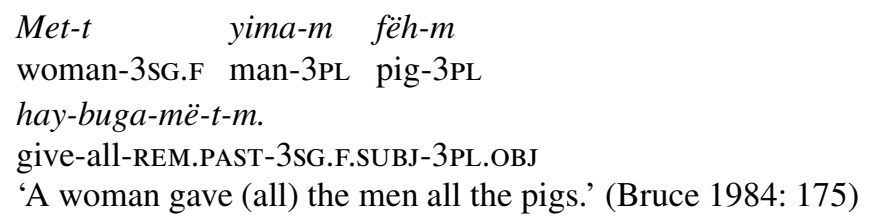

While it could be questioned whether the object suffix $-m$ in (7) really refers to the men and not to the pigs, example (8) shows the relationship unequivocally. The oblique phrase indicating location occurs post-verbally, showing that Alamblak is not strictly V-final.

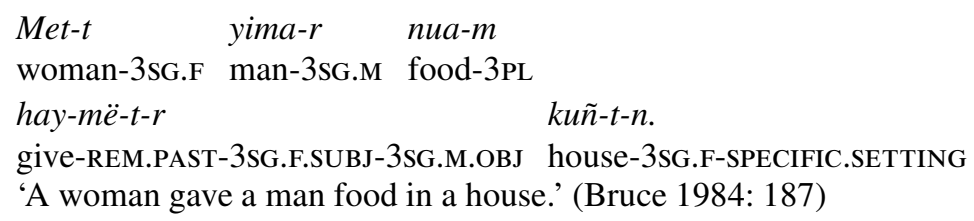


In Alamblak, the 'give' verb has suppletive stems for different tenses, but not for the person of the recipient, which is invariably cross-referenced by a regular object suffix (Bruce 1984: 145; for paradigms see Bruce 1984: 316-317).

Yessan-Mayo (Foreman 1974) is a member of the Tama subgroup of the Sepik family (Ross 2000, Foley 2005: 127). The language has no verbal affixation for any argument. The verb carries only suffixes for direction, aspect, and tense and a prefix $m i$ - that marks emphasis (Foreman 1974: 37). Both recipient and beneficiary constituents are marked by the postpositional clitic - $n i$, which also marks spatial goal, as illustrated in (9).
a. Yere nim sini rim-ni pere-ki yaw-im.
yesterday 1PL again 3PL-GOAL canoe-LOC go.up-FAR.PAST 'Yesterday we all went up again to them by canoe.' (Foreman 1974: 106)
b. An ri-ni awes nuwa-n a-m. 1sG 3sG.M-GOAL food give-and eat-FAR.PAST 'I gave him food to eat.' (Foreman 1974: 109; for verb endings, see Foreman 1974: 38, 43)
c. An ri-ni por wuri pi-ti.
1sG 3sG.M-GOAL pig one shoot-FUT
'I will shoot a pig for him.' (Foreman 1974: 109)

Since human direct objects in Yessan-Mayo receive the same marking, as illustrated in (10), one could argue that the verb nuwa 'give' governs two direct objects, a primary object expressing the recipient and a secondary object expressing the gift. According to Foley (1986: 174) it is a common practice of languages of the Sepik to mark animate undergoers with the dative case. Hence, in Table A-2 of the Appendix I give a positive value in the column indicating that the recipient can be marked as a direct object. ${ }^{4}$

\footnotetext{
4. Alternatively one could analyze the recipient of a ditransitive verb as an indirect-object construction, since the theme or gift is not flagged. Assuming that $-n i$ is one form with one meaning, the consequence of this analysis would be that animates cannot function as DO of a monotransitive verb, but have to be marked as an oblique object. As one reviewer points out, referring to the standard analysis of Spanish "personal $a$ ", another option is to assume polysemy for this marker between an indirect object (dative) marker and an animate object marker. However, although Yessan-Mayo lacks the indexation of the flagged recipient as found in Gizrra $(5 \mathrm{a}, \mathrm{b})$, it is clear that the recipient is marked like the animate direct object of a monotransitive verb.
} 


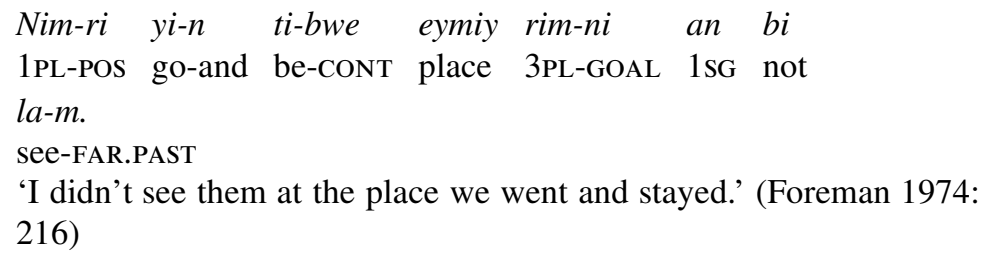

To conclude, the six languages reviewed in this section illustrate that the Human Interaction perspective (with neutral alignment for the nominal constituents) is the only option, regardless of whether (or how) the primary object is indexed on the verb.

\section{Choice between Human Interaction and Object Manipulation}

\subsection{Papuan dispreferences}

In Tables A-1 and A-2 of the Appendix, I show that there are only four out of the 33 TNG and seven out of 39 non-TNG languages that allow a choice between the two perspectives with the same verb. These options are illustrated for TNG Korowai and non-TNG Arammba in Section 4.2. For a few non-TNG languages (Sulka and Kuot) I have explicit evidence that they allow a choice between these alignments, but only by employing different verbs. Section 4.3 shows these options for Sulka, comparing the Human Interaction perspective with the only option in neighboring Mali. Section 4.4 is devoted to a minority of languages that have Object Manipulation as their only perspective.

\subsection{Choice between HI and OM with the same verb}

The verb morphology in Korowai, a (marginal) member of the Awyu-Dumut family (van Enk \& de Vries 1997: 9) has [V-TAM-A] as its template. In other words, there is no indexing of the direct object. As (11) and (12) show, Korowai can express the recipient as the direct object or as an oblique.

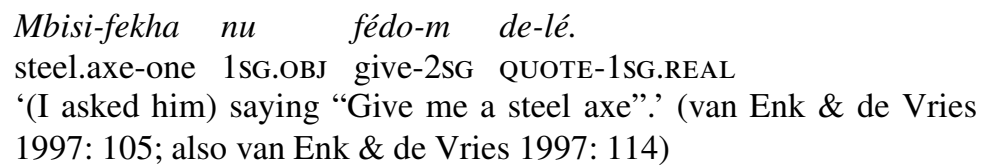

The oblique phrase for the recipient of 'give' does not employ the optional object form with -khata, but rather the postposition -tekhe (-lekhe intervocalically; van Enk \& de Vries 1997: 83), which is analyzed as a "relational noun on its way to becoming a nominal case suffix with cause, purpose, recipient, addressee, and beneficiary phrases" (van Enk \& de Vries 1997: 82). 
$\begin{array}{llll}\mathrm{Nu} & \text { if-e-kha } & \text { misafi gup-tekhé fédo-p. } \\ \text { 1SG.SUBJ this-LNK-CONN thing 2sG-to give-1sG.INTENT }\end{array}$

'I want to give these things to you.' (van Enk \& de Vries 1997: 82, 107)

Arammba (Boevé \& Boevé 2003), a member of the Morehead family of the Trans-Fly area, has a verbal prefix to index the direct object and a suffix indicating subject/actor in a portmanteau with tense and aspect. Pronouns in Arammba come in three sets: (i) ergative, which is marked in most cases by a suffix -ne; (ii) absolutive; and (iii) oblique, which occurs as a prefix to inalienable nouns and with postpositions, as in Table 2.

Verb stems come in two variants, a limited action root and a common root. The limited action root signals (i) there is only a single instance of the action; (ii) the action is restricted in time, intensity, or amount; and (iii) the number of participants is restricted. For example, when a plural subject suffix is used on a limited action root, the subject argument is interpreted to be dual, rather than plural in number. When a plural object prefix is attached to a limited root, then the object argument is interpreted as dual.

In addition to the free pronoun sets, there are absolutive prefixes on verbs in portmanteau morphemes, indicating tense-aspect. For each tense there are two sets, a strong and a weak variant, each conditioned by the number of objects, the intensity of action, or the person of the actor-subject, which is marked by a portmanteau suffix. These absolutive prefixes are the only locus in Arammba where gender is marked, and 2nd and 3rd person plural are collapsed. Thus, the stem variation follows an ergative pattern, as do the prefixes, but the suffixes follow a nominative pattern, indicating both person/number of $\mathrm{A}$ and $\mathrm{S}$, but not of O. Hence, verbal marking of arguments is quite complex with the mixing ergative and nominative patterns, reminiscent of what Foley (1986: 128) has shown for Kiwai (and as also seen in Gizrra).

In Table 2 I list only those prefixes that are used for WEAK PAST COMPLETIVE and PERFECT tenses.

Table 2. Pronominal sets in Arammba (after Boevé \& Boevé 2003: 33, 54)

\begin{tabular}{llllll}
\hline & ERGATIVE & ABSOLUTIVE & OBLIQUE & PX PAST COMPLETIVE & PX PERFECT \\
\hline 1SG & gene & gye & $n d u-$ & xuf- & tàw- \\
2SG & bene & $b e$ & $m b u-$ & $\tilde{n} g a ̀ f-~$ & ndan- \\
3SG.M & binó/nafo & $b i$ & $n a f-$ & tháf-/thef- & thà-/the- \\
3SG.F & & & gúf- & de- \\
1PL & nine & $n i$ & $n d a-$ & $\tilde{n} g e f-$ & $n d e n-$ \\
2PL & bene & $b e$ & $m b a-$ & sàf-/sef- & sa-/se- \\
3PL & bine/nafa & $b i$ & $n a f a-$ & & \\
\hline
\end{tabular}


The verb translated as 'give' has two variants, mand $\sim$ mnd is the limited action root, mainly used for temporary transfers, and the common root rino indicates a more permanent gift. mand $\sim$ mnd 'give' may take an absolutive prefix that cross-references the recipient (the nominal constituent is always flagged as an oblique) in the same way as the object of a monotransitive verb is indexed, as shown in (13).
a. Ngarú-wó ge
twa-rnamb- $\varnothing$.
man-ERG 1sG.ABS 1SG.ABS-hit-3sg.IMM.PAST

'The man hit me.' (Marco Boevé \& Katawer Baku, personal communication, 6 May 2008)

b. Ndu ngam-o ndu-n fari

1SG.POSs mother-ERG 1SG-OBL string

twa-mand- $\varnothing$.

1SG.ABS-give-3SG.IMM.PAST

'My mother gave the string to me.' (Marco Boevé \& Katawer

Baku, personal communication, 6 May 2008)

The same form may also index the gift, if the recipient is not expressed or only as an afterthought, as in (14).

(14) Nafo to nga ndjondjo ndamba de-mnd-ax

3SG PAST one thing small 3sG.ABS-give.LTD-REM.PAST

(ndu-nambo).

1SG-TO.HUMAN

'He gave something small (to me).' (Marco Boevé \& Katawer Baku, p.c. 6 May 2008)

The option of cross-referencing either the gift or the recipient by the verbal prefix is also available for rino, only given as a COMMON root. In (15a) and (15b) it is not acceptable to delete the oblique pronominal constituent $n d u-n$.

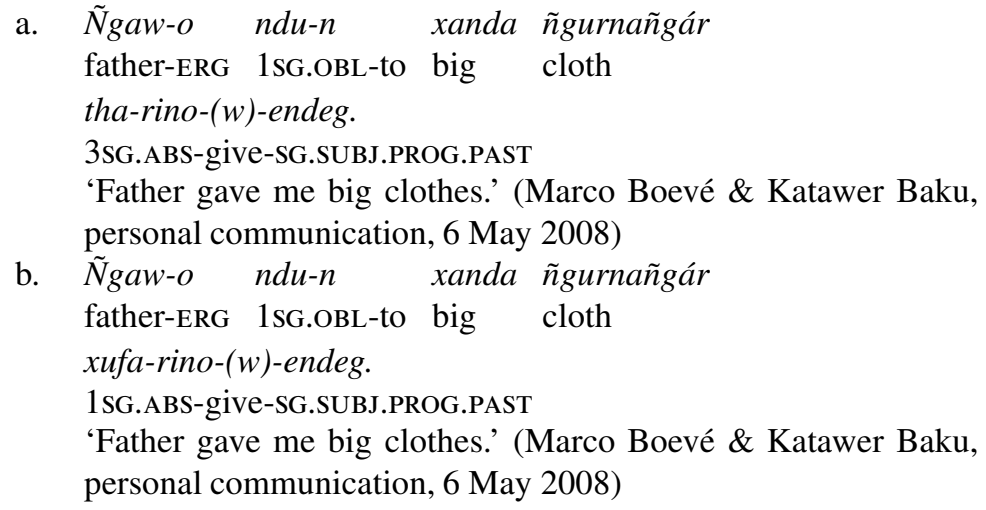


A beneficiary is treated the same way as a recipient. The nominal constituent is always flagged as an oblique, but indexed on the verb by a regular object prefix, as shown in (16).

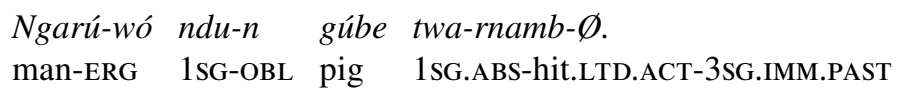

Ngarú-wó ndu-n gúbe twa-rnamb-Ø. man-ERG 1sG-OBL pig 1sG.ABS-hit.LTD.ACT-3SG.IMM.PAST 'The man killed a pig for me.' (Marco Boevé \& Katawer Baku, personal communication, 6 May 2008)

In other words, the nominal constituents are flagged according to the Object Manipulation perspective (indirective alignment, (a) in Figure 1), but the indexing on the verb indicates either an Object Manipulation or a Human Interaction perspective, depending on how much the speaker wants to focus on either the gift, as in (14) and (15a), or the recipient, as in (13b) and (15b).

Similarly, the choice between the two perspectives is the result of pragmatic factors in other languages. For example, saliency of recipient is responsible for recipient as Do in Korafe (Farr 1999: 133), and in Duna (San Roque 2008: 105) partial or temporary transfer of gift correlates with the recipient expressed as an oblique constituent (see Supplementary Online Materials).

\subsection{Choice between HI and OM employing different verbs}

Sulka (Schneider 1942, Reesink 2005) is an isolate spoken along Wide Bay in East New Britain, with a considerable number of contact-induced features from neighboring Oceanic languages, of which the article set $a$ 'SG', $o$ 'PL', $e$ 'PROPER NOUN' is perhaps the most striking. It is an SVO language with very little verbal morphology, but its Papuan origin can be seen in its prolific irregular number marking on nouns.

The only verb morphology in Sulka involves pronominal proclitics that are pormanteau morphemes that indicate the person/number of subject, status (realis, irrealis), aspect (for the realis status: perfective and imperfective), and a transitivizing suffix - Vm with some allomorphy (Reesink 2005: 165). Note the following:

$$
\begin{aligned}
& O \text { guela ngat=katlay-em } \quad \text { a morek. } \\
& \text { PL dog 3PL.PFV=eat.raw-TRVZ SG pig } \\
& \text { 'The dogs ate/bit the pig.' (Reesink 2005: 166) }
\end{aligned}
$$

The recipient of the verb ëën 'give' is always an oblique constituent, marked by the preposition ngang, as in (18).

$$
\begin{aligned}
& Y=\dddot{e} \ddot{n} \text { anieto ngang e Maria? } \\
& \text { 2sG.PFV=give what to PN Maria } \\
& \text { 'What did you give to Mary?' (author's fieldnotes) }
\end{aligned}
$$


The same construction is used for a beneficiary, as shown in:

$$
\begin{array}{llll}
Y \text { - } a=k \text {-ëën-kim } & o & \text { suku ngang erie? } \\
\text { 2SG-IPFV=SEQ-give-on.top PL tobacco for/to who }
\end{array}
$$

'For whom did you buy the tobacco?' (Schneider 1942: 464)

However, another verb for the GIVE event requires the recipient as direct object and the gift as an oblique constituent. This is translated by Schneider (1942: 122) as geben, beschenken 'give, present', and is exemplified in:

$$
\begin{aligned}
& \text { T-a=klang ka nopia orom o vиo. } \\
& \text { 3SG-IPFV=give 3sG.POS brother with PL betelnut.PL } \\
& \text { 'He gives his brother betelnuts.' (Schneider 1942: 122) }
\end{aligned}
$$

Although the free translation in (20) follows Schneider's German, a translation that better reflects the Sulka sense is 'he supplies/provides his brother with betelnuts', since the gift is clearly not a direct object. This conceptualization is similar to the only possible 'give' construction in neighboring Mali.

Mali (Stebbins 2011) is one of the five Baining languages, spoken on the Gazelle Peninsula of New Britain. As with other Papuan languages of New Britain, Mali has basically an SVO constituent order. It is a split-S language, with agentive (pro)nominal subjects preceding the verb, and undergoer subjects and objects occurring postverbally. There are three sets of concordial pronouns: Class I and II pronouns indicate the person, number, and gender of the agentive subject argument, with Class II pronouns indicating non-past tense (Stebbins 2011: 54). Class III pronouns are used for the undergoer argument, i.e., object of verb or preposition, or undergoer subject (Stebbins 2011:44).

Verbs may be simple or complex, ${ }^{5}$ and both may have a concordial pronoun referencing the object suffixed, as shown in what Stebbins characterizes as a "typical basic transitive clause" (Stebbins 2011: 42):

$$
\begin{array}{lll}
\ldots & d \bar{e} \quad \text { cha thachi... } \\
& d a \quad k a \quad \text { that }=k i \\
\text { and 3sG.M.I } & \text { get.FUT=3sG.F.III(OBJ) } \\
\text { '... and he gets her.' (Stebbins 2011: 43) }
\end{array}
$$

The GIVE event is expressed in Mali by the verb bon $\sim$ von 'give.PRESENT $\sim$ NON.PRESENT', with the recipient as direct object and the gift expressed as an oblique argument, marked by a preposition. This preposition may be $n a$, also used to mark the instrument, or $d / t \bar{e} m$ 'at' which marks themes and goals (Stebbins 2011: 123). For example, von $+n a$ in (22):

5. Complex verbs incorporate prepositions into lexicalized complexes similar in some ways to phrasal verbs in Germanic languages, as observed by Stebbins. 


$\begin{array}{llll}\text { Cha } & \text { von } & \text { ma } & \text { Lèmuthēmga nava } \\ \text { ka } & \text { von } & \text { ma } & \text { Lēmuthēmga na=av=a }\end{array}$

3SG.M.I give.NON-PRES ART Lēmuthēmga PREP=3sG.M.POS=SPEC vilēchi pilēch-ki gun-SG.F 'He gave Lēmuthēmga (lit., "[the one] who [is] clean”) his gun.' (Stebbins 2011: 268)

The preposition $d / t \bar{e} m$ glossed as THEME, GOAL, PATH (Stebbins 2011: 67), may be compounded with the verb stem with the gift as object. In such cases the article is encliticized to the complex verb + preposition, as in (23), where there is no (pro)nominal reference to the recipient.

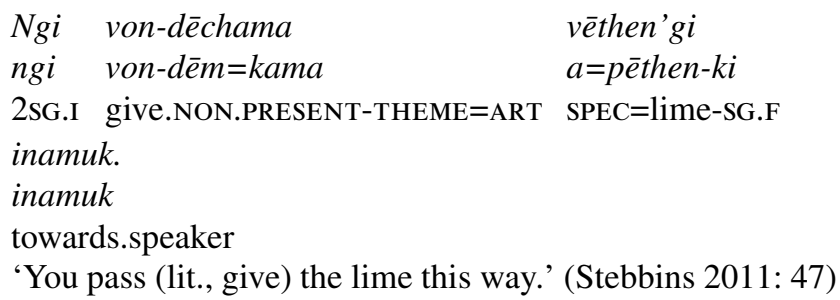

Alternatively, the recipient is the direct object and the gift expressed as a separate oblique argument:

$$
\begin{aligned}
& \text {.. Dē chi von'ga thēm[ngēt }] \text {. } \\
& \text {.. de } k i \text { von-ka temmenget } \\
& \text { and 3SG.F.II give.NON.PRESENT-3SG.M.III(OBJ) THEME=3.N.III }
\end{aligned}
$$

In (24) the gift is indicated by the anaphoric pronoun $n g \bar{e} t$ ' 3. N.OBJECT' governed by the preposition têm. This preposition is strongly associated with the gift; it is not required when this is omitted and only the recipient is expressed, as in (25).

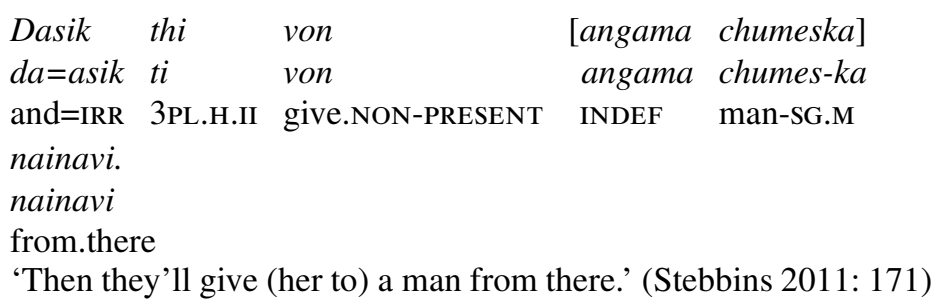

There are many languages in my sample that have Human Interaction as the only perspective (Section 3), and therefore exhibit neutral alignment as far 
as flagging of constituents is concerned. However, Mali is the only language that obligatorily flags the theme object, while treating the recipient as primary object. Thus, the free translations of the linguistic construction expressing the GIVE event in Mali do not really do justice to the genius of the language. Stebbins (2011: 47) has also remarked on this, where the verb bon $\sim$ von seems to be more like 'provide recipient with gift'.

Possibly, the secundative alignments in Papuan Sulka and Mali are due to areal diffusion from neighbouring Oceanic languages of the Gazelle Peninsula of New Britain and New Ireland. Blansitt (1984: 141) quotes from unpublished material by Lee on Mandak, an Oceanic language of New Ireland, to illustrate what he calls "Transferred as Instrumental or Ablative" showing that "give him with money' and 'hit it with bushknife' have the same morphosyntactic structure. Siar of New Ireland (Rowe 2005: 78) and its relative Tolai, spoken on the Gazelle Peninsula (Mosel 1984), both have a verb tar 'give' which has an Object Manipulation perspective (indirective alignment), and an alternative form tabar with a true secundative alignment. Mosel states that tabar (with its secundative alignment) is used if the thing given is food or a present, as in (26).

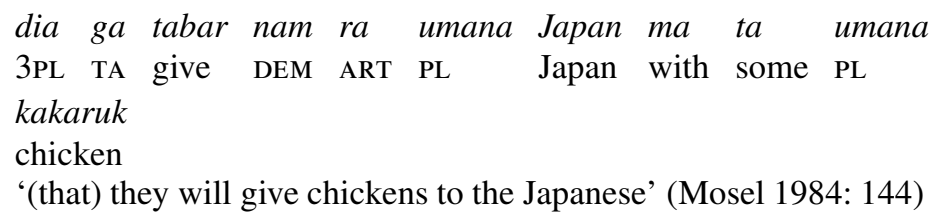

\subsection{Object Manipulation as only perspective}

A minority of languages in my sample of 72 Papuan languages have as their only option the Object Manipulation perspective. Three TNG (Kaluli, Suena, Wambon) and eight non-TNG (Bauzi, Hatam, I'saka, Kol, Lavukaleve, Meyah, Moi, Orya) languages express only the gift with the same formal marking as a DO of a monotransitive predicate. There does not seem to be a clear correlation between the word order and the morphological template of the verb, except that in most of these languages, whether SOV or SVO, there is no object affix on the verb.

The examples in this section represent SOV languages: the TNG language Suena with no object affix and non-TNG I'saka which has an undergoer suffix.

Suena belongs to the Binandere family of the TNG family (D. Wilson 1974). The only argument indexed on the verb is the agent/subject by means of a suffix. The person/number suffix follows the tense marker and is followed by a mood suffix. Dual to and 1st person plural inclusive kai and exclusive kare are separate from the person/number marker (D. Wilson 1974: 48, 59). Examples with both gift and recipient expressed in one clause have the recipient obliquely marked by a demonstrative form and the suffix -re, as in (27). 


$$
\begin{array}{lll}
\text { Suna ni-so bamubake ami-re pot-i. } \\
\text { dog 2sG-POS big } & \text { DEM-TO give-IMP } \\
\text { 'Give it to your big dog.' (D. Wilson 1974: 79) }
\end{array}
$$

A natural way to express the GIVE event seems to be a SVC-like clause sequence with the verb pot glossed as 'give' or 'put' (D. Wilson 1974: 44-48) as first and 'take' as second predicate, making explicit that the recipient has taken control over the gift, as in (28).

$$
\begin{aligned}
& \text { Moni pot-e-n-a} \quad \text { pum- } i-a \\
& \text { money give-TODAY.PAST-1SG-IND take-3sG-IND } \\
& \text { 'I gave him money and he took it.' (D. Wilson 1974: 44) }
\end{aligned}
$$

I'saka is a remote member of the Skou family, spoken in the northwest of Papua New Guinea (Donohue \& San Roque 2004: 6). It has a basic SOV constituent order with some leakage of (in)direct objects to post-verbal position, and $[\mathrm{A}-\mathrm{V}-\mathrm{U}]$ verbal morphology. I'saka has four different pronoun sets: unmarked, nominative, accusative, and possessive pronouns. The verb carries a prefix to index the subject and suffixes for human objects or a different set for dative, encoding recipient, beneficiary, goal, experiencer, and possessor (Donohue \& San Roque 2004: 63). Compare the following examples:
a. Nai d-esi
d-epa-ki
boy 1sG-carry 1sG-put-3sG.M.HUM.OBJ leg-leg
'I'll hold the boy on my lap.' (Donohue \& San Roque 2004: 62)
b. $\mathrm{Pa} n$-ani-ka Mak.
bag 1sG-give-3sG.M.DAT Mark
'I gave a bag to Mark.' (Donohue \& San Roque 2004: 64)

The accusative free pronoun and the dative verbal suffix contrast according to the degree of transitivity (Donohue \& San Roque 2004: 65). This is illustrated in (30a) and (30b), where the absence of the dative suffix conveys a high-transitive event:
a. Nana d-àu d-elei-ma mama.
$1 \mathrm{SG} \quad 1 \mathrm{sG}-\mathrm{come}$ 1SG-see-2sG.DAT $2 \mathrm{SG}$
'I've come to see you.' (Donohue \& San Roque 2004: 64)
b. Nana bi d-elei.
$1 \mathrm{SG}$ 2sG.ACC 1sG-see
'I'm watching you.' (Donohue \& San Roque 2004: 65)

The dative set is also used to express a beneficiary, as in (31a), or a possessor, as Donohue \& San Roque (2004: 64) claim for (31b). The latter example may well be an instance of beneficiary or malefactive. 
a. Kerosin d-ai-ma.

kerosene 1sG-get-2sG.DAT

'I'll get some kerosene for you.' (Donohue \& San Roque 2004: 64)

b. Nana a d-o-ma.

1 sG pig.M 1sG-do.M.OBJ-2sG.DAT

'I shot your pig.' (Donohue \& San Roque 2004: 64)

In sum, (29b) shows that I'saka does not require a dative marking for human objects, as in some Sepik languages. And this means that the 'give' construction (29b) does not express the recipient as direct object, but rather as an oblique, further strengthened by the requirement that a (pro)nominal constituent occurs post-verbally (Donohue \& San Roque 2004: 63). Thus, I'saka exhibits indirective alignment or the Object Manipulation perspective.

\section{Suppletion for recipient}

Comrie (2003) has shown that the phenomenon of suppletive forms of the verb 'give' for recipient is found in a substantial number of languages, from many different families across the globe. Some of his examples come from a few Papuan languages, and one Oceanic language from the New Guinea area, Saliba (see Margetts 2008).

Amele is analyzed (Roberts 1998), and quoted (Newman 2002, Comrie 2003), as a language in which the verb 'give' is a zero morpheme, which has been replaced by the indirect object affix, occurring on other verbs (Roberts 1998: 25-27). Although there are other languages for which 'give' has been analyzed as constituted by a zero stem, I would argue for the reverse process, namely that the minimal verb 'give' is attached to other stems to express the recipient or beneficiary (or malefactive, depending on the semantic-pragmatic context).

In order to make my argument, which will allow comparisons with other languages of the Madang and Finisterre-Huon regions, I need to present rather detailed material from Amele.

Roberts (1998: 19) states that the noun phrase recipient can only be expressed by object agreement on the verb. It can be marked as either a core argument by direct object agreement or a dative argument by indirect object agreement, depending on the semantics of the verb itself. In order to determine whether the object agreement in 'give' is direct or indirect, Roberts (1998: 23) compares 'give' with the way recipient is marked in other verbs. There is in fact only a small difference between the DO and Io marking on verbs and the stems of the verb 'give', as illustrated in Table 3, based on Roberts (1998: 10, 24), with slightly different morpheme breaks. 
Table 3. Direct object (Do) and indirect object (IO) agreement in Amele

\begin{tabular}{|c|c|c|c|c|c|c|c|}
\hline & \multicolumn{2}{|c|}{$\begin{array}{l}\text { 'to give' } \\
\text { IOAgr }\end{array}$} & \multirow{2}{*}{$\begin{array}{l}\text { 'to share' } \\
\text { IoAgr } \\
\text { siw-it-ec }\end{array}$} & \multicolumn{2}{|c|}{$\begin{array}{l}\text { wen 'hunger' } \\
\text { DoAgr }\end{array}$} & \multirow{2}{*}{$\begin{array}{l}\text { 'to show' } \\
\text { DoAgr } \\
i h a c-t-e c\end{array}$} & \multirow{2}{*}{$\begin{array}{l}\text { 'to divide' } \\
\text { DoAgr } \\
\text { cesaw-it-ec }\end{array}$} \\
\hline $1 \mathrm{SG}$ & $i t-e c$ & 'to me' & & $t-e c$ & 'does me' & & \\
\hline $2 \mathrm{SG}$ & $i h-e c$ & 'to you' & siw-ih-ec & $h-e c$ & 'does you' & ihac-h-ec & cesaw-ih-ec \\
\hline $3 \mathrm{SG}$ & $u t-e c$ & 'to him/her' & $s i w-i t-o c$ & $d-o c$ & 'does him/her' & ihac-d-oc & cesaw-ud-ec \\
\hline $1 \mathrm{DU}$ & $i l-e c$ & 'to us two' & siw-il-ec & $l-e c$ & 'does us two' & ihac-l-ec & cesaw-il-ec \\
\hline $2 \mathrm{DU}$ & $a l-e c$ & 'to you two' & siw-i-al-ec & al-ec & 'does you two' & ihac-al-ec & cesaw-al-ec \\
\hline $3 \mathrm{DU}$ & $a l-e c$ & $\begin{array}{l}\text { 'to them } \\
\text { two' }\end{array}$ & siw-i-al-ec & $a l-e c$ & $\begin{array}{l}\text { 'does them } \\
\text { two' }\end{array}$ & ihac-al-ec & cesaw-al-ec \\
\hline 1PL & $i g-e c$ & 'to us' & siw-ig-ec & $g-e c$ & 'does us' & ihac-g-ec & cesaw-ig-ec \\
\hline $2 \mathrm{PL}$ & $a d-e c$ & 'to you' & siw-i-ad-ec & $a d-e c$ & 'does you' & ihac-ad-ec & cesaw-ad-ec \\
\hline 3PL & $a d-e c$ & 'to them' & siw-i-ad-ec & $a d-e c$ & 'does them' & ihac-ad-ec & cesaw-ad-ec \\
\hline
\end{tabular}

Note that the difference between the generic verbs 'give' and 'do' is the presence of the initial vowel $i$ - ( $\sim u$ - for 3sG), except for 2/3DU and 2/3PL. This could be analyzed as an elision in the free verb, preceding $/ a /$, because it is explicit when the verb is attached to another verb stem, as in the dual and plural recipients (or benefactives) with the verb siw 'share', siw-i-al/ad-ec 'to share for you/them, dual/plural'.

Roberts begins by claiming that the verb stem is a zero morpheme, and that the whole concept is expressed by an indirect object prefix, referring to the recipient, and a suffix identifying person-number of the subject to the verb (in this case, a zero stem) and TAM categories (in this case, the imperative mood), as in (32).

$$
\text { Ceb it-ag-a! }
$$

betelnut 1sG.IO-2sG.SUBJ-IMP

'Give me betelnut! (Roberts 1998: 1)

As Roberts develops his description of the verb 'to give' in Amele, he claims that the verb stem is not zero, but that the Io agreement morpheme has taken on the function of verb stem, to which a regular Do marker can be suffixed, as in:

$$
\begin{aligned}
& \text { Uqa ho eu it-ad-ei-a. } \\
& \text { 3sG pig that 1sG.IO-3PL.DO-3sG.SUBJ-TODAY.PAST } \\
& \text { 'He gave me those pigs.' (Roberts 1998: 25) }
\end{aligned}
$$

However, I have some questions about his analysis. First of all, the dative marker $i$ that shows up in various examples preceding an oblique object morpheme, as in (33), does not seem all that different from the free form of the 
verb 'give' in other examples. Compare it-ag-a '1sG.IO-2sG.SUBJ-IMP' in (32) and $i$-t-ag-a 'DAT-1SG.OO-2SG.SUBJ-TODAY.PAST' in (34).

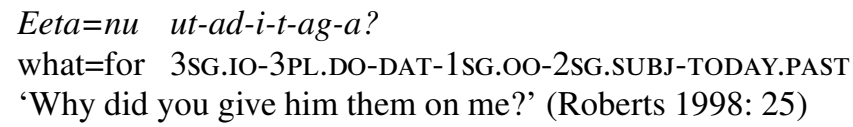

Thus, it could also be argued that the benefactive/malefactive marking on verbs, as in (35), is simply the verb 'give', with some incidental loss of the initial vowel /i-/ in 2nd and 3rd person dual and plural forms of the independent verb (see Section 7).

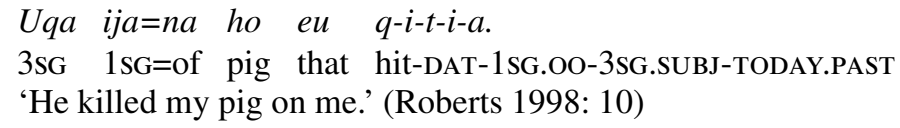

The minimal morphemic form of 'give' is not exceptional. Other languages, geographically close to Amele, may not have a complete null stem for 'give', but their forms are still quite minimal. In addition, and as in Amele, the form for 'to give' can be suffixed as an applicative to other verb stems to express a benefactive (or malefactive) relation.

As observed by Comrie (2003: 279) and Roberts (1998: 1), the comparative work by Z'graggen (1980: 130) shows that a great number of languages in the Madang subgroups have zero or minimal verb stems for 'give', always indexing person-number of the recipient, with the result that the verb 'give' appears to have suppletive stems. Table 4 provides some examples.

The comparison with object affixation in these languages reveals different patterns. For example, Bargam and Usan both have Do prefixes, mainly for animate objects, on transitive verbs. However, Waskia has no object affixation,

Table 4. GIVE in some Madang languages

\begin{tabular}{llllllll}
\hline RECIPIENT & Bargam & Mauwake & Usan & Waskia & Koromu & Siroi & Amele \\
\hline 1SG & $y a-g-$ & $y i-$ & $y e-s-$ & asi- & si-se- & $s-$ & $i t-$ \\
2SG & $n i-g-$ & $n i-$ & $n e-t-$ & kisi- & te-ne- & tin-/tan- & ih- \\
3SG & $u-g-$ & $i w-$ & $u-t-$ & tuw-/tuiy- & tu- & $t-$ & $u t-$ \\
$1 \mathrm{PL}$ & $i-g-$ & $y i-$ & in-dar- & idi- & si-seka- & sing- & ig- \\
2PL & $n e-g-$ & $n i-$ & an-dar- & $i d i-$ & te-teka- & ting- & ad- \\
3PL & $n e-g-$ & $w i-$ & wuri-s- & idi- & te-nek- & ning- & ad- \\
\hline
\end{tabular}

Sources: Hepner (2006: 86) for Bargam; Berghäll (2010: 147) for Mauwake; Reesink (1987: 111) for Usan; Ross \& Paol (1978: 43) for Waskia; Priestley (2001: 107) for Koromu; Wells (1979: 35) for Siroi; Roberts (1998: 10) for Amele. 
while Koromu, Siroi, and Amele have Do suffixes. On the other hand, Koromu appears to have suppletive stems for recipient of 'give', which are further suffixed with regular Do suffixes again cross-referencing the recipient. These languages belong to various subgroups of the large Madang group: Usan is classified as belonging to the Croisilles linkage (Ross 2000: 109); Amele as a member of the Mabuso family; and Koromu, also known as Kesawai, as member of the Sub-Rai Coast family (Ross 2000: 108, 109, 112).

The shift from object prefix to suffix, which Foley (2000: 377) claimed was the canonical verb structure for Trans New Guinea languages, is found in the Finisterre-Huon languages. McElhanon (1973: 43) reports that in general the Finisterre languages show a predominance of prefixal forms, while the Huon Peninsula show a predominance of suffixal forms. He gives evidence (McElhanon 1973: 46) that all languages of the Huon Peninsula exhibit the same close connection between the lexical verb 'give' and beneficiary suffixes on other verbs.

Suppletion for the person/number of the recipient is largely found in languages of the Madang and Finisterre-Huon families. Outside this area, this phenomenon is found in Kewa and Menya. Umanakaina (Evensen 1996) may be a third language with suppletion, having 3sG kwe-ya versus - ge-ya for other persons and numbers. But as shown in the Supplementary Online Materials, the verb $g e(-y a)$ could easily be interpreted as a regularly paradigmatic (i.e., canonical; see Corbett 2007) form with inflection of the direct object $=$ recipient prefix attached to the stem, and thus would not involve suppletion at all.

Even in some of the Madang and Huon languages, the claimed suppletion seems to be due to a phonologically very minimal stem, which can be parsed as a single form for the whole paradigm, as in Bargam - $g$-, or Nabak - $a$ - (see Supplementary Online Materials) showing canonical inflection (Corbett 2007). That is why Berghäll (2010: 147) prefers to call the five verbs in Mauwake that inherently cross-reference the object "object cross-referencing" rather than suppletive, because the verb root and object prefixes can still be recognized. The solution I offer for the putative zero stem in Amele and Roberts's counterintuitive claim that the indirect object suffix has been "promoted" to a full lexical verb, has as a result suppletive stems for all person/number distinctions of the recipient, with 2nd and 3rd persons plural (and dual) conflated.

Canonical suppletion (Corbett 2007) involves a similar meaning expressed by morphologically unrelatable forms. In Kewa and all other Engan languages (Karl Franklin, personal communication), Menya, and a few Huon languages, with Selepet as representative, the suppletion distinguishes 1st and 2nd person versus 3rd person recipient, as summarized in Table 5. In the Madang languages of my sample the distinction is between all singular persons, or 1st person on the one hand and 2nd and 3rd on the other, with an extra stem in some cases for plural recipients, as shown in Table 4. For other Huon languages with 
Table 5. Suppletion for recipient in some TNG languages

\begin{tabular}{lllll}
\hline Recipient & Kewa & Menya & Umanakaina & Selepet \\
\hline 1 or 2 & gi & tap & $-g e$ & $-i h i$ \\
3 & kaláa & $i$ ('do') & kwe (only 3sG) & wang (only 3sG) \\
$1 \mathrm{PL}$ & gi & tap & $-g e$ & $(C)-k i$ \\
$2 \mathrm{PL}$ & gi & tap & $-g e$ & $(C)-k i$ \\
3PL & kaláa & $i$ & $-g e$ & $(C)-k i$ \\
\hline
\end{tabular}

suppletion for 3sG, Ono and Kâte, see McElhanon (1973: 46). The Ok languages, Mian and Telefol, have suppletive stems for aspect, not for recipient.

All the Madang and Finisterre-Huon languages have the serial verb construction [V + 'give'] to express the beneficiary. In some, this construction is (still) bi-clausal, as in Kobon, while in others the suppletive stems have been lexicalized (see Section 7). This is true even to the extent that Roberts claimed a reversed grammaticalization path for Amele, i.e., from a bound beneficiary morpheme to an independent verb expressing the GIVE event.

As shown in this section, suppletion for recipient is particularly found in the Madang and Finisterre-Huon subgroups of TNG. Whether the Engan family and the Angan family (Menya and Tainae) are just exceptions outside this northern area is not known. Only two non-TNG languages in my sample have suppletive verb stems for recipient, Ambulas and Yélî Dnye. Ambulas shares this feature and the actual forms with Manambu, another member of the Ndu family (see Aikhenvald 2008). Again, it is not known whether suppletion for recipient is more widespread in non-TNG families than the Ndu family and the isolate Yélî Dnye.

\section{Three arguments indexed on the verb}

\subsection{A typological rarum}

In both major groupings we find languages with the typologically unusual feature of indexing three arguments on the verb. The Ok languages Telefol and Mian and Amele of TNG and the unrelated non-TNG languages Yimas and Mairasi have affixation for giver, recipient, and gift.

\subsection{TNG Mian and Telefol}

Mian (a.k.a. Mianmin; Smith \& Weston 1974, Smith 1977) is a member of the Ok family and a member of the larger TNG family, as first observed by Alan Healey (1964; see also Ross 2000: 134, 2005: 22). A more recent description of Mian is given by Fedden (2007). For my examples I will refer to Fedden 
Table 6. Object prefixes in Mian (from Fedden 2010: 460, 468)

\begin{tabular}{llllll}
\hline & $\begin{array}{l}\text { Object } \\
\text { prefixes }\end{array}$ & $\begin{array}{l}\text { Object } \\
\text { prefixes for } \\
-n \hat{a} \text { ' 'hit, kill } \\
(\mathrm{PFV})\end{array}$ & $\begin{array}{l}\text { Object } \\
\text { prefixes for } \\
-e \text { 'hit, kill } \\
\text { (IPFV) }\end{array}$ & $\begin{array}{l}\text { Recipient } \\
\text { suffixes for } \\
-k a \text {-'give.IPFV' }\end{array}$ & $\begin{array}{l}\text { Recipient } \\
\text { suffixes for } \\
-\hat{u} b \text { '- } \\
\text { 'give.PFV' }\end{array}$ \\
\hline 1SG & $n a-$ & $n e-$ & $n-$ & $-n e$ & $-n e(n)$ \\
2SG & $k a-$ & $k e-$ & $k-$ & $-k e$ & $-k e(n)$ \\
3SG.M & $a-$ & $a-$ & $(h) a-e[>(h) a-]$ & $-b a$ & $-a(n)$ \\
3SG.F & $w a-$ & $w a-\sim u-$ & $w-$ & $-w e$ & $-o(n)$ \\
PL.AN & $y a-$ & $y e-\sim i-$ & $y-$ & $-y e$ & $-e(n)$ \\
\hline
\end{tabular}

Note: Mian has stem accented and off-stem accented verbs, -nâ 'hit.PFV' belongs to the latter; the tonal melody attaches to the syllable directly following the stem. Also, the imperfective verb - $e$ 'hit' only has C-prefixes.

(2010), since in this paper all relevant details with regard to the GIVE event are discussed most clearly.

Mian has an SOV constituent order and [U-V-BEN-TAM-A-TNS] as its verbal morphology structure. About two thirds of the verbs have different stems for perfective and imperfective. The subject of intransitives is marked as the subject of transitives by a verbal suffix, as, for example, the allomorphs io and $i b$ for '2/3PL.ANIMATE.SUBJECT' in (36a) and (36b).

$$
\begin{aligned}
& \text { a. Yole on-s-io=be. } \\
& \text { well go.PFV-REM.PAST-2/3PL.AN.SUBJ=DECL } \\
& \text { 'Well, they went.' (Fedden 2010: 457) } \\
& \text { b. Yole éil=e a-nâ-s-ib-e? } \\
& \text { well pig=SG.M 3sG.M.OBJ-kill.PFV-REM.PAST-2/3PL.AN.SUBJ=Q } \\
& \text { 'Well, did they kill the pig?' (Fedden 2010: 457) }
\end{aligned}
$$

Transitive verbs are prefixed with a classificatory prefix or an object prefix. There are five verbs that take an object prefix to cross-reference both animate and inanimate objects. These are relevant for the discussion of the 'give' verb, so I replicate Fedden's Tables 2 and 4 here in Table 6.

The 'give' verb in Mian has the form $\hat{u} b$ '- for the perfective. It obligatorily takes a classificatory prefix to cross-reference the gift, while the recipient is cross-referenced by a suffix. As shown in Table 6, these are quite similar to the object prefixes, but glossed as REC in (37). Fedden (2010: 461) asserts,

the verb - $\hat{u} b$ '- 'give (PFV)' shows neutral flagging. As in monotransitive clauses, none of the overt argument NPs [...] are marked for their syntactic roles [...]. With respect to indexing [...], we find indirective alignment, i.e. the theme is 
indexed in the same way as the patient in a transitive clause, namely by a prefix on the verb, while the recipient is encoded by a suffix.

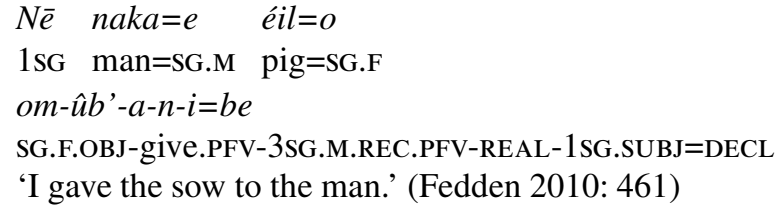

The 'give' verb in Mian is suppletive when marking aspect. The imperfective 'give' is - $k a-$, which requires a classificatory prefix for the gift and a slightly different set of suffixes, compared with the recipient of perfective $-\hat{u} b$ '- (see Table 6). Consider:

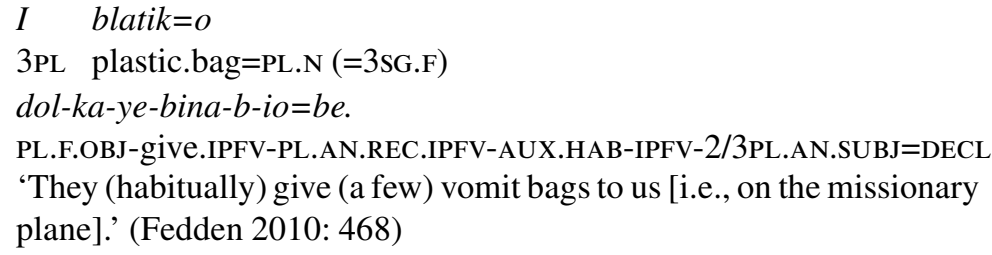

A beneficiary in Mian can be expressed by a tight serial verb construction (compound) with the verb - $\hat{u} b$ '- 'give' in second position.

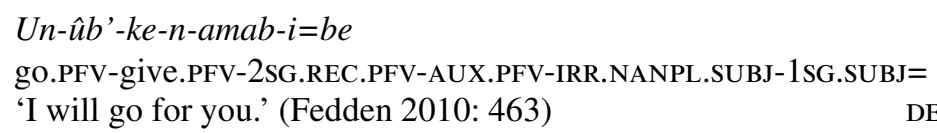

This can only occur in the perfective. In the imperfective the verb is directly suffixed by the recipient suffixes used for imperfective 'give' $k a-$, as in (40).

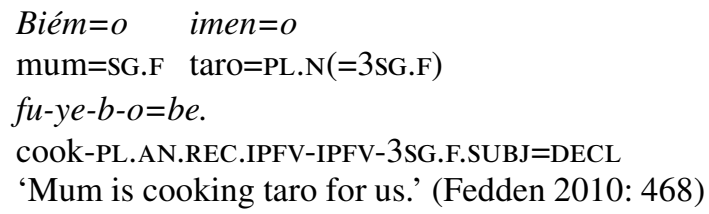

\subsection{Non-TNG Yimas and Mairasi}

Yimas of the Lower Sepik family (Foley 1991) is perhaps the best known Papuan language, due to the prolific publications by Bill Foley. He claims (Foley 1991: 369) that Yimas is a non-configurational language at the clausal level. The hierarchically ordered pattern of its verbal morphology is rather complex and unusual in that it allows affixation of three core arguments for ditransitive 
verbs. As I discuss a few ditransitive constructions I will argue against some of Foley's claims of homophony.

The structure of [THEME-A-DAT-V] holds for 1 st and 2 nd person dative arguments. Although I follow Foley in his terminology, the dative prefix is in fact the regular direct object prefix (which Foley (1991: 208) states as "homophonous"), as shown by pa- '1sG.OBJ' in (41a, b), I represent these with consistent glosses, rather than OBJECT in one instance and DATIVE in another.

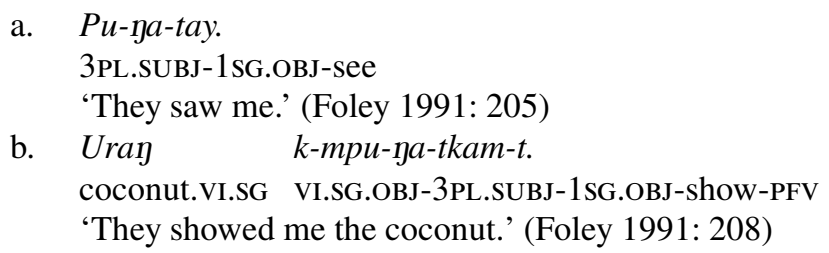

This morphological structure of the verb holds for four basic ditransitive verbs (Foley 1991: 208): pa- 'give', $i$ - 'tell someone', tkam- 'show', and pul'rub on'. The reason why Foley claims homophony for these object prefixes is that for the 3rd person there are different sets. Not only different sets, but 3rd person datives are suffixed rather than prefixed to the verb.

While 1st and 2nd person follow a nominative-accusative alignment (or rather, nominative-dative, with Foley (1991: 209) following Silverstein), as in (42a), 3rd person prefixes follow an ergative absolutive alignment: $m p \dot{i}$ - for A, impa- for $\mathrm{S}$ and $\mathrm{O}$, and the suffix -mpn for DATIVE, as in (42b).

$$
\begin{aligned}
& \text { a. Makaw wa-mpi-nkul-na-t. } \\
& \text { fish(sp).IX.SG IX.SG.OBJ-3DU.SUBJ-2DU.OBJ-give-PFV } \\
& \text { 'They two gave you two makau.' (Foley 1991: 213) } \\
& \text { b. Makaw wa-nkran-na-r-mpn. } \\
& \text { fish(sp).IX.SG IX.SG.OBJ-2DU.SUBJ-give-PFV-3DL.DAT } \\
& \text { 'You two gave them both makau.' (Foley 1991: 213) }
\end{aligned}
$$

According to Foley (1991: 211), a salient feature of the three 3rd person dative suffixes (-(n)akn 'singular', -mpn 'dual', and -mpun 'plural') is the final - $n$ which, in Foley's words, "of course, bears a transparent relationship to the oblique suffix $-n \sim-n a n$ ". My judgement is stronger: it is not just a transparent relationship, but an identity, because, equally important, the dative 3rd person "must always occur in absolute final position in the verb" (Foley 1991: 211), even following the TAM suffix. The oblique suffix $-n \sim-n a n$ is described by Foley (1991: 165) as the single nominal case marker used to mark a range of peripheral, adverbial-like case uses, such as instruments, locatives, and temporals; and, I would add, recipients and beneficiaries.

The same position is occupied by a 3rd person beneficiary when the agent and the benefitting participant are in the same place at the same time (Foley 
1991: 308), which explains the comitative -tan between the A (subject) prefix and the verb stem in (43). ${ }^{6}$

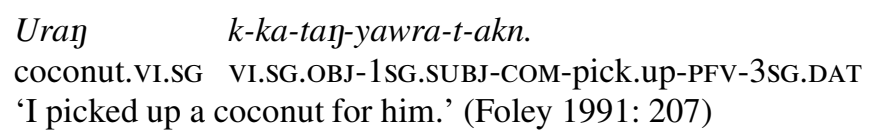

A construction with the comitative tay conveys an action carried out in close proximity of or collaboration with another participant. However, when the action is carried out by a person acting individually for the benefit of someone else, Yimas requires a tight serial verb construction (or compound) with the verb $y a$ 'give'. In this case, as in other languages where such a serialization is grammaticalized (see Section 7), the verb 'give' does not necessarily imply a physical transfer of the gift, as shown by:

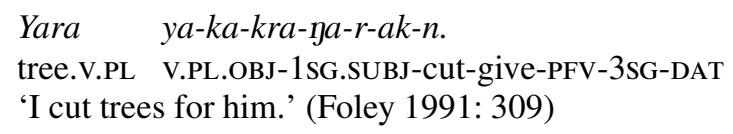

The examples with the verbs 'show' (41b) and 'give' (42a, b) show that 1st and 2 nd person recipients are indexed according to a $\mathrm{HI}$ alignment, but that $3 \mathrm{rd}$ person recipients require an OM (indirective) alignment.

Mairasi is spoken in the neck of the Bird's Head of the Indonesian province Papua. It forms a small family with Semimi and a few other languages (Peckham 2000: 74) and its affiliation to the TNG family is questionable (Ross 2000: 241), hence I consider this language as non-TNG. Together with Menggwa Dla, it is exceptional in my sample in marking actor and undergoer both by suffixes in this order [V-A-U], as in (45).

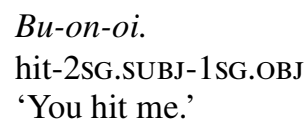

Mairasi has different intransitive verb classes, based on whether $\mathrm{S}$ is marked by a prefix or a suffix. Motion verbs, such as -sov 'go', but also cognition and perception verbs, such as -ror 'know', -tom 'see', and -vi 'hear', mark the subject by prefixes. Other intransitive verbs take a suffix, but in this case a

6. Constructions with this comitative element lead Foley to claim a significant difference in Yimas culture, stating that "a person is not defined individually, as an autonomous source of action, but is viewed as a locus of collective responsibilities, mediated through exchange relations" (Foley 1991: 308). In my view, such claims, also expressed in Foley (1997: 260-285) with respect to, for example, the Papua New Guinea Highlands ethnolinguistic group Gahuku, risk to exoticize Papuan cultures in magnifying certain social obligations and practices. Individuals as "loci of collective responsibility" are part of any human culture, in my view. 
Table 7. Pronominal sets in Mairasi (from Peckham 2000)

\begin{tabular}{lllllll}
\hline & Free & 'go' & 'fall' & 'sleep' & 'drop it' & Object suffix \\
\hline 1SG & omo & o-sov & imbi-on & tevj-om & imbi-om-nai & -oi \\
2SG & neme & ne-sov & imbi-en & tevj-on & imbi-on-nai & -ei \\
3SG & nani & na-sov & imbi-en & tevj-emi & imbi-em-nyai & -nai \\
1PL & eeme & ee-sov & imbi-es & tevj-osi & imbi-os-nyai & -sem \\
2PL & eme & $e-s o v$ & imbi-ei & tevj-oi & imbi-o-nyai & -em \\
3PL & na'a & ne-sov & imbi-en & tevj-emi & imbi-em-nyai & -nev \\
\hline
\end{tabular}

difference in control is marked by different sets. Verbs denoting events over which the subject has less control, such as imbi- 'fall', take a set characterized by final $-n$ for $1 \mathrm{sG}$ and 3rd person, and the vowel $e$ for 1PL and 2 nd person. Intransitive verbs such as tevj- 'sleep' are considered to be more under control, and have a different set: - $m$ for 1SG and 3rd person, and the vowel $o$ for 1PL and 2nd person, plus a final vowel $i$ for $3 \mathrm{sg}$ and all plural forms. This latter set is also used to cross-reference the subject of controlled transitive verbs.

A sizeable number of verbs are ambitransitive, and 'fall' is one of these. Transitively, of course, it can be translated as 'drop', and it takes the agentive subject set. In Table 7 I present an example of each, together with the free pronouns. Note that the final $i$ of 3sG and all plural agentive subject suffixes metathesizes with the 3sG nai object suffix: $-\mathrm{VCi}+$ nai $>-\mathrm{VC}+$ nyai. Here are some examples:

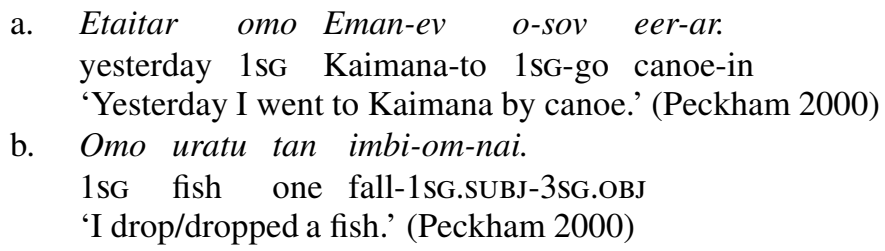

The verb for 'give' is highly suppletive for the subject person/number, not for the recipient as in a number of other Papuan languages (see Section 5): 1sG ov, 2sG evon, 3sg etom, 1PL evosi, 2PL evoni, 3PL etomi. Apparently, these suppletive forms may be prefixed to index the gift, which is an (in)animate object. The regular postverbal object marker is reserved for the recipient. The following examples have different agents and recipients and are highlighted to show that Mairasi allows verbal marking for three core arguments:

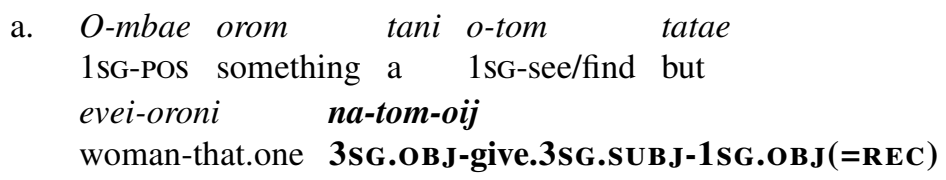




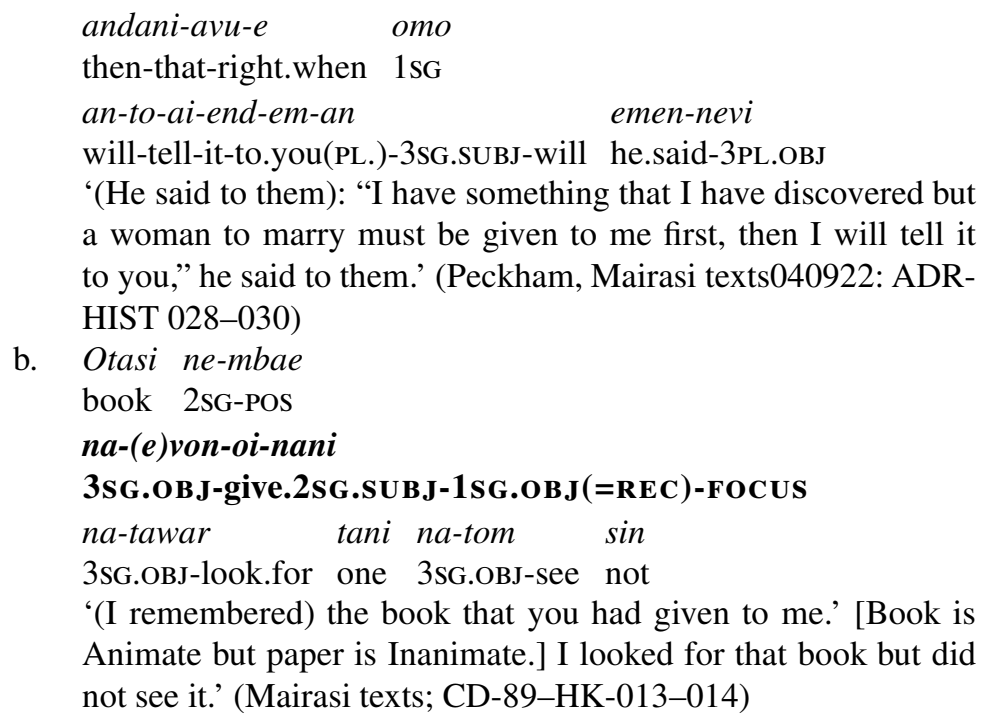

Neither the preliminary Mairasi grammar nor the Mairasi texts provide information on the expression of beneficiaries.

\section{7. 'Give' is not universal as a three-place predicate}

\subsection{Papuan exceptionality}

Moi and Maybrat of the Bird's Head and the TNG language Koiari are languages that straddle the dichotomy of the Human Interaction and Object Manipulation perspectives. They basically employ both perspectives in a biclausal construction by first handling the gift, then affecting the recipient. In fact, Moi requires a serial verb construction with three verbs, each indexed by a subject prefix for the giver, the gift, and the recipient, as shown in (48).

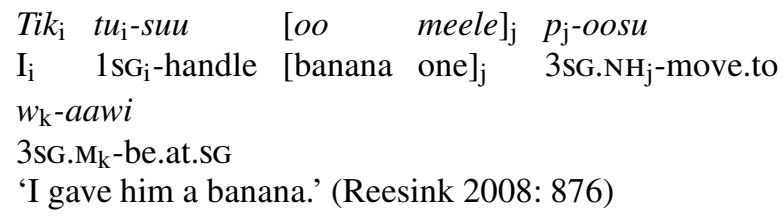

It follows that these languages are counterexamples to the claim that 'give' verbs have always three arguments, as seems to be the position of Pinker (1989) and Gleitman (1990). Another challenge to universal claims regarding the expresssion of the GIVE event is provided by languages that lack a dedicated etymon for this concept. Thus, in Section 7.2 biclausal constructions are presented, and in Section 7.3 I illustrate the lack of a dedicated 'give' verb. 


\subsection{Biclausal constructions}

In Maybrat (Dol 2007), spoken in the western center of the Bird's Head, the concept of GIVE has to be expressed by two actions carried out by the subject: $\mathrm{X}$ takes Y, X gives to Z (Dol 2007: 218). So the two verbs carry the same prefix, as shown in (49).

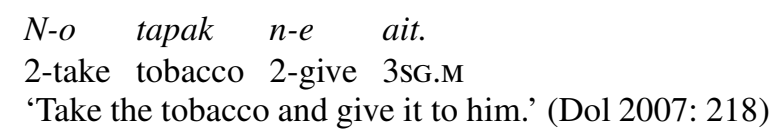

While Maybrat is totally unique among the languages of the Bird's Head in its linguistic configuration of the GIVE event requiring a sequence of two predicates with one subject/actor (compare the TNG language Koiari for a similar construction), beneficiaries are expressed by a construction akin to what we find in Moi. The form $m$-kah is used as a preposition translatable by 'with, to, for'. Phonologically it is unmistakably of verbal origin with the 3sG.F/3PL prefix $m$ - as invariant first element. It can not be used for a situation as verbalized in (49), but it expresses instrument, as in (50a), and beneficiary or recipient/goal constituents, as in (50b).
a. T-ai m-kah ara.
1sG-hit 3sG.F/PL-with tree/wood
'I hit with a stick.' (Dol 2007: 80)
b. Au m-kom am m-kah m-mè.
3sG.F 3sG.F/PL-write letter 3sG.F/PL-for 3sG.F/PL-mother
'She writes a letter to/for her mother.' (Dol 2007: 205)

Koiari (Dutton 2003), spoken to the northeast of Port Moresby in Papua New Guinea and belonging to the Koiarian family (Ross 2000: 82), marks the number of object of transitive verbs by means of a suffix. This pattern follows an ergative-absolutive alignment, because the same set is used for subjects of intransitive action verbs and all state verbs.

The number suffix for S/O is followed by a portmanteau morpheme, following a nominative-accusative alignment, indicating TAM categories and person and number of the subject of action verbs and some state verbs and the experiencers of other state verbs (Dutton 2003: 344). To illustrate:
a. Da ere-va-nu.
1SG see-SG.OBJ-1/3sG.SUBJ.PFV
'I saw it.' (Dutton 2003: 340)
b. No ere-va-nua.
1PL see-SG.OBJ-2SG/1/2/3.PL.SUBJ.PFV
'We saw it.' (Dutton 2003: 340) 


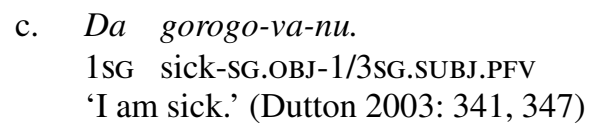

Dutton (2003: 339, Footnote 3) states explicitly that there are no ditransitive verbs in Koiari. The recipient of $m o$ 'give' is a direct object, and the gift is introduced as the direct object of the verb $m a$ 'get' in a preceding predication, as in (52a) and (52b). In these examples, the same subject-immediate sequence suffix -me conditions the vowel of the verb stem to change to [i] (Dutton 2003: 357, Footnote 17).

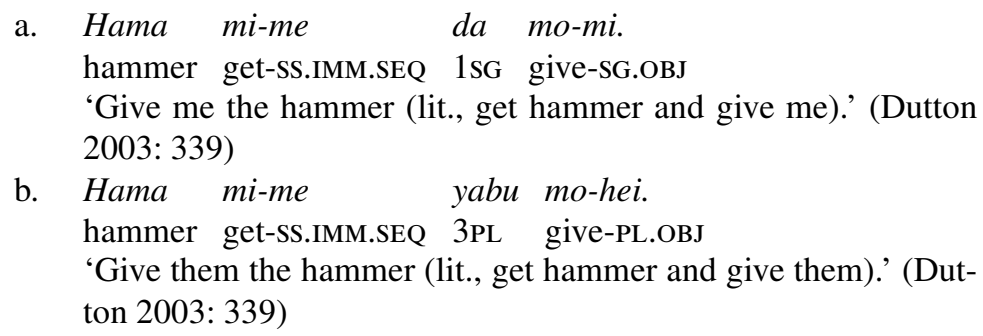

Biclausal 'give' constructions are also found in the non-TNG family of Timor-Alor-Pantar. In a recent paper Klamer \& Schapper (forthcoming) show a diachronic pathway for 'give' constructions from biclausal or serial verb constructions [GIFT take/come recipient give] to an "oblique strategy" encoding both theme and recipient arguments of a single ditransitive verb.

\subsection{No dedicated etymon}

Hatam forms a small family with the virtually extinct Mansim in the eastern Bird's Head (Reesink (ed.) 2002). In this language, the concept of GIVE is expressed by a verb that basically means something like 'take/get' a theme/object, as illustrated by (53).

$$
\begin{array}{llll}
\text { A-juk } & \text { na-nti } & \text { a-yai } & \text { hum. } \\
\text { 2sG-descend } & \text { 2sG-self } & \text { 2sG-take } & \text { fire } \\
\text { 'You come down yourself (and) get fire.' (Reesink 1999: 159) }
\end{array}
$$

The recipient of the GIVE event is expressed as object of a preposition in all the languages of the eastern Bird's Head (Hatam, and Mansim; Meyah and Sougb; and Mpur) as well as in Abun of the western Bird's Head. In these languages the verb translated as 'give' has a more general meaning, closer to 'take, get'. Here are just two comparable examples from Hatam (54a) and Mpur (54b). 


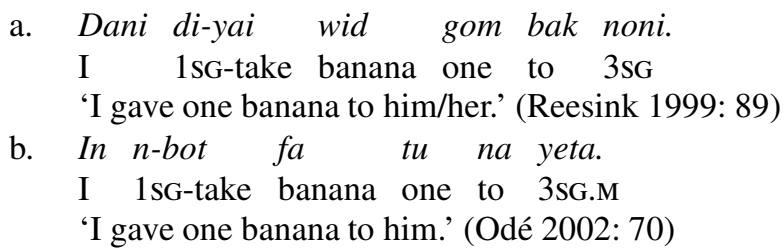

Beneficiaries employ the same construction in these languages; in Hatam with the same preposition bak as the recipient. In Meyah and its relative Sougb, different prepositions are used.

Accordingly, the languages of the Bird's Head, as well as Orya (Fields 1997, 2000), lack a basic 'give' verb. The etyma in these languages do not have 'give' as their core meaning; instead a term is employed that has control and changing the location as its core meaning. As Newman (1996: 13) observes, "GIVE is not an irreducible concept, but easily understood as the transference of a thing from the control of one person to the control of another". Indeed, the examples in Section 7.2 show that changing the location of a gift and its causation are components that may be distributed over two predicates (compare the composition of 'give' in Kamoro presented in Section 3.2). This suggests that in languages discussed in Sections 7.2 and 7.3 control of handling is the basic meaning, further specified for direction from or towards another location, and this information can be spread over two monotransitive predicates or integrated in one clause.

\section{Beneficiary as $[\mathrm{V}+$ give $]$ construction}

A small number of languages may express the beneficiary by means of a construction which involves 'give', although this is a typologically very common phenomenon. Instances are found in three non-TNG languages (Abau, Alamblak, and Ambulas) and six TNG languages (Amele, Mian, Selepet, Siroi, Usan, and Waskia). A few other TNG languages employ some other verb or particle in a similar construction (Duna, Fore, Hua, Koromu, Nabak).

In Alamblak (Bruce 1984), expressing a beneficiary requires a tight serial verb compound of a verb (which may be a one-/two- or three-place verb) with hay 'give', cross-referencing the beneficiary with the object suffix (Bruce 1984: 231):

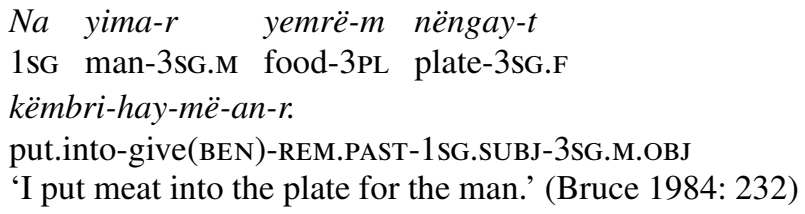

Another valency increasing process, the causative which requires hay $\sim h a \sim$ 
$k a$ as prefix, is restricted to intransitive-like verbs (Bruce 1984: 231), but it may co-occur with the beneficiary marking instance of hay 'give', as shown by (56).

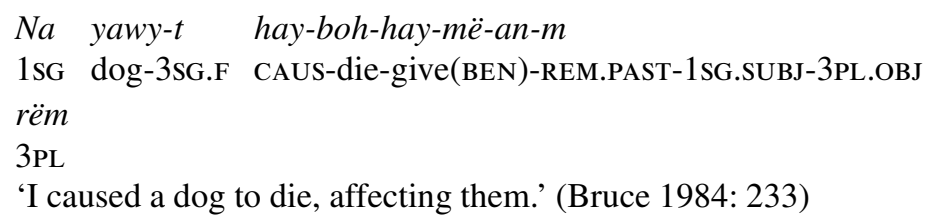

Comparison of three TNG languages suggests a grammaticalization pathway for this construction: biclausal (Kobon) $>$ compound serial verb construction (Selepet) $>$ verbal suffix (Kewa).

In Kobon, "objects which function as patient and those which function as recipient/beneficiary are not distinguished from one another morphologically or syntactically" (Davies 1989: 109), as illustrated in (57). The result is two direct objects positioned normally between the subject/actor and the verb.

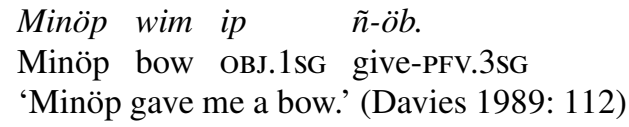

With respect to the expression of a beneficiary, Davies observes (1989: 112) that "the beneficiary can be expressed as a possessor of an object noun phrase if these functions are pragmatically equivalent" (58a); if not, the beneficiary must be expressed in a separate clause, as in (58b). This actually involves a coordinated sequence with the first verb marked for SAME SUBJECT. This is different from languages where the two verbs are serialized and lexicalized as a morphological unit.

a. Nipe wim yad g-ab.

$3 \mathrm{sG}$ bow $1 \mathrm{sg}(\mathrm{POS})$ do-PRES.3sG

'He is making my bow'/'He is making a bow for me.' (Davies 1989: 112)

b. Nipe wim g-öm ip ñi-nab.

3sg bow do-ss.3sg 1sg(OBJ) give-FUt.3sg

'He is making a bow and will give it to me.' (Davies 1989: 112)

According to McElhanon (1972: 38-41; 1973: 43-50), Selepet and most other Huon languages have three or more subclasses of transitive verbs that are defined by their object suffixes. Selepet object suffixes are based on the roots (McElhanon calls them subclass markers) $e k$ (Class I), ihi (Class II) and oho (Class III), specifying person and number by prefixes. For example, $n$-ek ' $1 \mathrm{sG}$ ', $n e-l-e k$ ' $1 \mathrm{DU}$ ', ne-n-ek '1PL' represent Class I. The 3sG allomorph of this object marker is zero; when the form $e k$ is attached to a zero morpheme it means 'see 
3sG'. "The subclass II object markers [based on ihi] are obviously related to the benefactive markers [...] the benefactive marker occurs as a first order verbal suffix and all forms are identical with the subclass II object makers except $3 \mathrm{~s}$ which has the form -wagi" (McElhanon 1972: 39). When the 3sG object marker ihi occurs by itself (McElhanon would say: attached to a zero morpheme) it can

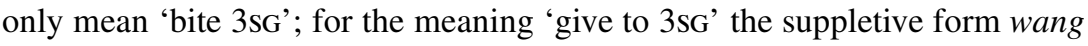
is used. The similar forms of -ihi 'bite, give' for other than 3rd person objects seem to be a case of accidental homonymy. When the subclass III object marker (based on -oho) is attached to a zero morpheme it means 'to hit' or 'to kill', but it has a suppletive form $k u$ for a $3 \mathrm{sg}$ object.

However, if we allow for lexicalized serial verb constructions involving any of these three verbs, it can be argued that Selepet, and by extension the other Huon languages, originally had the canonical object prefix of Trans New Guinea, as pointed out by Foley (2000: 378). Thus, rather than analyzing the three verbs in Selepet as having zero stems with object markers as "suffixes", as McElhanon (1972: 40) does: Ø-ku-nihi-ap [hit-it-for.me-he(IMM.PAST)' for 'he killed it for me', it seems more economical to assume a zero prefix or suppletive form for 3sG, as in (59a), showing its relation to the lexical verb 'give' in (59b).

\author{
a. Ku-n-ihi-ap. \\ 3sG.hit-1sG.OBJ-give-3SG.IMMEDIATE.PAST \\ 'He hit/killed it for me.' (see McElhanon 1972: 40) \\ b. N-ihi-ap. \\ 1sG.OBJ-give/bite-3sG.IMMEDIATE.PAST \\ 'He gave it to me; it bit me.' (see McElhanon 1973: 43)
}

These examples show that the Huon-language Selepet agrees with the Madang languages (Siroi, Amele, Waskia, Usan) in its configuration [V + 'give'] to mark a beneficiary.

In Kewa, belonging to the Engan family (Franklin 1971, Ross 2000: 127), the verb translating 'give' does not behave differently syntactically from other transitive verbs, as illustrated by the monotransitive object $n i ́$ ' $1 \mathrm{sG}^{\text {' }}$ in (60a) and the same form referring to the recipient in (60b).

$$
\begin{aligned}
& \text { a. Áá-para raí láápo-mé ní tá-pe. } \\
& \text { man-and axe two-AGENT 1sG hit-3DL.PAST } \\
& \text { 'The man and the axe hit me.' (Franklin 1971: 63) } \\
& \text { b. Áá-para naakí láápo-mé ní gé-pe. } \\
& \text { man-and boy two-AGENT 1sG give-3DL.PAST } \\
& \text { 'The man and the boy gave (it) to me.' (Franklin 1971: 62) }
\end{aligned}
$$

The beneficiary can be marked on the verb. In fact, Franklin $(1971: 39,40)$ gives two full paradigms of portmanteau suffixes for all person-number actors 
and different tenses and the imperative, distinguishing alterocentric and egocentric benefaction. The egocentric set occurs only with active verb bases, and the alterocentric set is found on stative or derived verb bases. The alterocentric set is obligatory on active verbs when a beneficiary functions in the clause (Franklin 1971: 66), as illustrated in (61b).

Comparison of (60b) with (61a, b) shows that 'give' is morphologically aberrant, in that it has suppletive forms, gé-for 1st and 2nd person recipients, kálaafor 3rd person recipients. Examples $(61 \mathrm{a}, \mathrm{b})$ illustrate the morphological distinction between the egocentric and alterocentric beneficiaries. The historical source for the benefactive in proto-Engan is actually a suffix *-ka, but the $/ \mathrm{k} /$ is lost in Kewa (Karl Franklin, personal communication), leaving apparently a trace in the portmanteau suffixes: the lateral in /-lo/ 1sG.PRES.EGOCENTRIC is replaced by a fortis alveolar plosive in /-to/ for 1sG.PRES.ALTEROCENTRIC. I suggest that this fortification reflects proto-Engan *-ka, which is likely a reflex of the verb 'give' (see further my speculative reconstruction in the Supplementary Online Materials).
a. Né-mé maapú-para móni kálaa-lo.
1SG-AGENT garden-LOC money give-1SG.PRES.EGO
'I am giving (him) money in the garden.' (Franklin 1971: 66)
b. Né-mé maapú-para móni kálaa-to.
1SG-AGENT garden-LOC money give-1SG.PRES.ALTRO
'I am giving (him) money for the garden.' (Franklin 1971: 66)

\section{Conclusion}

In this article (and the Supplementary Online Materials) I have given an overview of GIVE constructions in 72 Papuan languages, divided into the main groupings of the Trans New Guinea family and non-TNG families. I have compared these with the morphosyntactic properties of transitive verbs. I have shown that there is an enormous diversity in verbal morphological templates, even when most Papuan languages have an SOV word order. Because less than ten percent of the total number of about 800 languages have been considered, one must be aware that there could be other phenomena of interest in the remaining languages that would lead to different conclusions. However, even on the basis of this small sample, some typologically interesting observations are offered.

(i) First of all, in the overwhelming majority of Papuan languages, the GIVE event is constructed according to the Human Interaction perspective (neutral or secundative alignment). The recipient is expressed as primary object of the verb that translates as 'give', and the gift as secondary object. This configuration is found as the only option in almost all (30/33) 
TNG languages, with the Ok family as an exception. In a number of languages this perspective requires suppletion for the person and/or number of the recipient.

The most important factor responsible for these facts is that Papuan languages predominantly index animate (human and higher animals) undergoers, and in many languages the affix for $3 \mathrm{sg}$ is zero. These facts suggest that in the majority of Papuan languages the Person-Animacy hierarchy (1st $>2$ nd $>3$ rd human $>3$ rd animal $>3$ rd inanimate) is the most important factor for expressing the recipient as primary object, as is also the case, for example, in Bantu languages (Hyman \& Duranti 1982: 224).

(ii) Very few (four) of the TNG languages allow a choice between the Human Interaction and Object Manipulation perspectives with the same verb, and only three TNG languages (Kaluli, Suena, Wambon) have Object Manipulation (indirective alignment) as their only option.

(iii) The Human Interaction perspective is also predominantly present among non-TNG languages (31/39), of which seven allow a choice between the two perspectives with the same verb translated as 'give'. Two isolates in the Bismarck Archipelago (Sulka and Kuot) allow the choice but employ different etyma.

(iv) In those languages that allow a choice between the gift or the recipient as direct object, the choice seems to be determined by pragmatic factors, such as focus on gift or recipient (Arammba), saliency of recipient (Korafe), and partial or temporary transfer of gift (Duna).

(v) Another language of the Bismarck Archipelago (Mali) has the strongest application of the Human Interaction perspective. Here the recipient is the only argument that can be expressed as direct object, the gift obligatorily being expressed by means of an oblique NP. As I have suggested (Section 4.2), this may reflect an areal feature shared by Oceanic languages of the Gazelle Peninsula and New Ireland.

(vi) The alternative perspective, Object Manipulation, as the only option for the GIVE event is found mainly in languages of the non-TNG families, scattered along what I identify as a North-Papuan expanse: languages of the Bird's Head (Moi, Hatam, Meyah), Bauzi, Orya, I'saka, Kol of East New Britain, and Lavukaleve of the Solomon Islands. Given the enormous geographical spread and multiple linguistic affiliations, it is highly unlikely that this represents anything more than a chance distribution.

(vii) A typologically rare phenomenon (Section 6) occurs in five languages that allow three arguments to be cross-referenced on the verb. In Yimas and the two Ok languages, this prefix/proclitic cross-references the class, determined by shape or substance, of the object transferred. In Mairasi, the 'give' verb suppletes for the agentive subject, and the normal position 
of the transitive object is suffix, hence in this case it cross-references the recipient, while the gift is prefixed to this verbal complex. Thus, it seems that in these four languages the third argument affixed on the verbs is a direct consequence of a (resumptive) pronominal reference to the theme object in an OV language. In the fifth language, Amele, the verbal affixation of three arguments - agentive subject as final suffix, recipient (indirect object) as first, and gift (direct object) as second affix (Section 5) - appears as the result of a lexicalized serial verb construction: [give to X, do Y (by) Z]. Again, the Person-Animacy hierarchy explains why the recipient is the primary object and the gift the secondary object.

The results reported here provide an addition to the overview of GIVE constructions and their geographical distribution as presented by Haspelmath (2011). Among the Papuan languages of the New Guinea area there is an overwhelming predominance of double-object and secondaryobject constructions (Human Interaction perspective), although the indirect-object pattern (Object Manipulation perspective) is also found, in some languages as choice, in others - as mentioned, mainly scattered in a few disparate lineages along the northern Papuan expanse - as sole construction.

(viii) Straddling the dichotomy of the two perspectives are Maybrat of the Bird's Head, some Timor-Alor-Pantar languages, and the TNG language Koiari. They basically employ both perspectives in a biclausal construction with two monotransitive verbs: first handle the gift, then affect the recipient. The Bird's Head languages and Orya lack a dedicated lexical item for GIVE. In these languages a more general etymon translatable as 'take' functions with an allative/beneficiary adposition as 'give', contrasting with an ablative adposition that expresses the source of the TAKE event.

These languages illustrate some of Newman's observations. He remarks: "giving is experientially basic, but conceptually complex" (Newman 1996: 254), and "the range of constructional possibilities of literal GIVE clauses in languages is further evidence of the internal complexity of the act of giving" (1996: 257). When Newman compares the GIVE and TAKE events and emphasizes the main distinction that TAKE lacks a giver, he discusses the various ways all three participants are integrated in one clause (Newman 1996: 254-262). However, Maybrat and Koiari require gift and recipient to be distributed over two clauses. Moi even requires a series of three predicates. While conceptually the GIVE event involves three participants, which I take as a cognitive universal, it is not the case that all languages have three-place predicates to express this. Thus, these languages form counterexamples to the claim that 'give' verbs universally have three arguments, which seems to be the position of Pinker 
(1989: 94) and Gleitman (1990). See also Evans \& Levinson (2009) for a similar challenge to Gleitman's "language universal".

(ix) The Human Interaction perspective is further illustrated by the way a beneficiary is expressed. A number of the TNG languages do this by means of a construction consisting of [V + 'give'], exhibiting a cline from a clearly biclausal construction, as in Kobon, via a serial verb construction, as in Usan and Selepet, to lexicalized forms, as the paradigmatic contrast between 'egocentric' and 'alterocentric' verbal affixes in Kewa.

(x) Some languages of various non-TNG families simply employ some direct object (or more general, undergoer) verbal affix to express the beneficiary. This is found in Abui and Klon of the Timor-Alor-Pantar group; Bukiyip and Kamasau of the Torricelli family; Yessan-Mayo and Yimas of the Sepik family; Marind, Arammba, and Bine of the South-Papuan area; and Motuna of Bougainville.

(xi) A configuration in which the beneficiary can only be an oblique argument is indicative of the Object Manipulation perspective. This appears as a strong feature in Papuan languages that have an SVO constituent order, but found only in a few regions of the northern non-TNG area: the Bird's Head, some Torricelli languages, and the Papuan languages of the Bismarck Archipelago.

(xii) Finally, the diversity that I have documented for $9 \%$ of the Papuan languages may reflect no more than some of the full diversity which exists in Papuan languages. The Supplementary Online Materials contain a section in which I outline, rather speculatively, possible cognate sets for 'give' in Papuan languages. A larger sample might give clearer patterns of genealogical relatedness or spread of alignment patterns through admixture. In addition, some minor patterns described here may turn out to be more widespread.

It may be tempting to explain the predominance of the Human Interaction perspective in Papuan languages by some cultural correlate. As I mentioned in the introduction, a visitor to any Papuan culture would be struck by the meticulous record keeping of people's creditors and debtors. However, this observation can be compared with similar tit-for-tat patterns in, for example, western cultures. I would emphasize that it is difficult, if not impossible, to find more concern for Human Interaction among the speakers of most TNG and nonTNG languages versus more cultural preoccupation with Object Manipulation in languages of other lineages. In other words, I repeat the caution of Newman (2002: 93), that we should not overestimate the extent to which culture and grammatical structures can be directly connected. 
Correspondence address: Max Planck Institute for Psycholinguistics, Postbus 310, $6500 \mathrm{AH}$ Nijmegen, The Netherlands; e-mail: ger.reesink@hccnet.nl.

Acknowledgements: This paper is a by-product of the NWO programme "Breaking the time barrier: Structural traces of the Sahul past", under the supervision of professors Pieter C. Muysken and Stephen C. Levinson, in which my colleague Michael Dunn and I were the main executing researchers (see Reesink et al. 2009). I would like to express my appreciation to Alan and Phyllis Healey for commenting on my first draft, based on Healey (1965a, b), and supplying me with updated materials and spelling conventions for Telefol. Similarly, Tonya Stebbins (for Mali) and Louise Baird (for Klon) have refined my sketches, based on prepublication versions of their grammars. I also wish to thank Angela Terrill, Leon Stassen, and three anonymous reviewers for comments of an earlier more extended version. They have helped me to provide a more concise form, which is supported by the more detailed sketches in the Supplementary Online Materials. This more concise version has benefitted greatly from comments, bibliographic references, and editorial improvements provided by three anonymous reviewers and Karl Franklin. The latter also provided editorial help for the Supplementary Online Materials.

Abbreviations: 1/2/3 1st/2nd/3rd person; A/ACT actor/agentive subject; ABS absolutive; ACC accusative; AN animate; ANT anterior; APPL applicative; ART article; ASO associative; ASs assertion; AUX auxiliary; BEN beneficiary; CAUS causative; CERT certainty; CL class; COMIT comitative; COMPL completive; COND conditional; CONN connective; CONT continuative; DAT dative; DECL declarative; DEF definite; DEM demonstrative; DL dual; Do direct object; DSO dissociative; DUR durative; DS different subject; EMPH emphatic; ERG ergative; EXC exclusive; $\mathrm{F}$ feminine; FOC focus; FUT future; GEN genitive; НАВ habitual; HUM human; IMM immediate; IMP imperative; INAN inanimate; INC inclusive; IND indicative; INDEF indefinite; INF infinitive; INS instrument; IO indirect object; IPFV imperfective; IRR irrealis; LIG ligature; LNK linker; LOC locative; LTD limited; M masculine; MF monofocal; MOM momentary; N neuter; NANPL non-animate plural; NEG negative; NH non-human; NM noun marker; o/OBJ object; OBL oblique; OO oblique object; PA past; PERM permanent; PFV perfective; PL plural; PN proper noun; POS possessive; PRES present; PROG progressive; PROX proximate; PUNCT punctiliar; Q question; R realis; RC relative clause; REC recipient; REM remote; S/SUBJ subject; SEQ sequential; ss same subject; SUB subordinate; TAM tense-aspect-mood; TNG Trans New Guinea; TNS tense; TOP topic; TR trial; TRANS transitive; TRVZ transitivizer; U undergoer; $\mathrm{V}$ verb; vis visible.

\section{Appendix}

Tables A-1 and A-2 list 33 TNG and 39 non-TNG languages in alphabetical order. Columns 3-5 indicate whether a language indexes the direct object of a monotransitive verb and, in each language the main morphological template for undergoer, verb stem, and agent/subject. Column 6 indicates whether the recipient in a ditransitive construction is marked in the same way as the DO of a monotransitive verb. Column 7 shows which perspective is present: HI signifies that a Human Interaction is the only option, om signifies that Object Manipulation is the only option; CHOICE means a language allows both perspectives; вотн means that both perspectives are equally salient. Column 8 gives information about suppletion and column 9 about whether the expression of the beneficiary as indexed on the verb or not. The final column gives the references to the supporting literature for my analysis. 


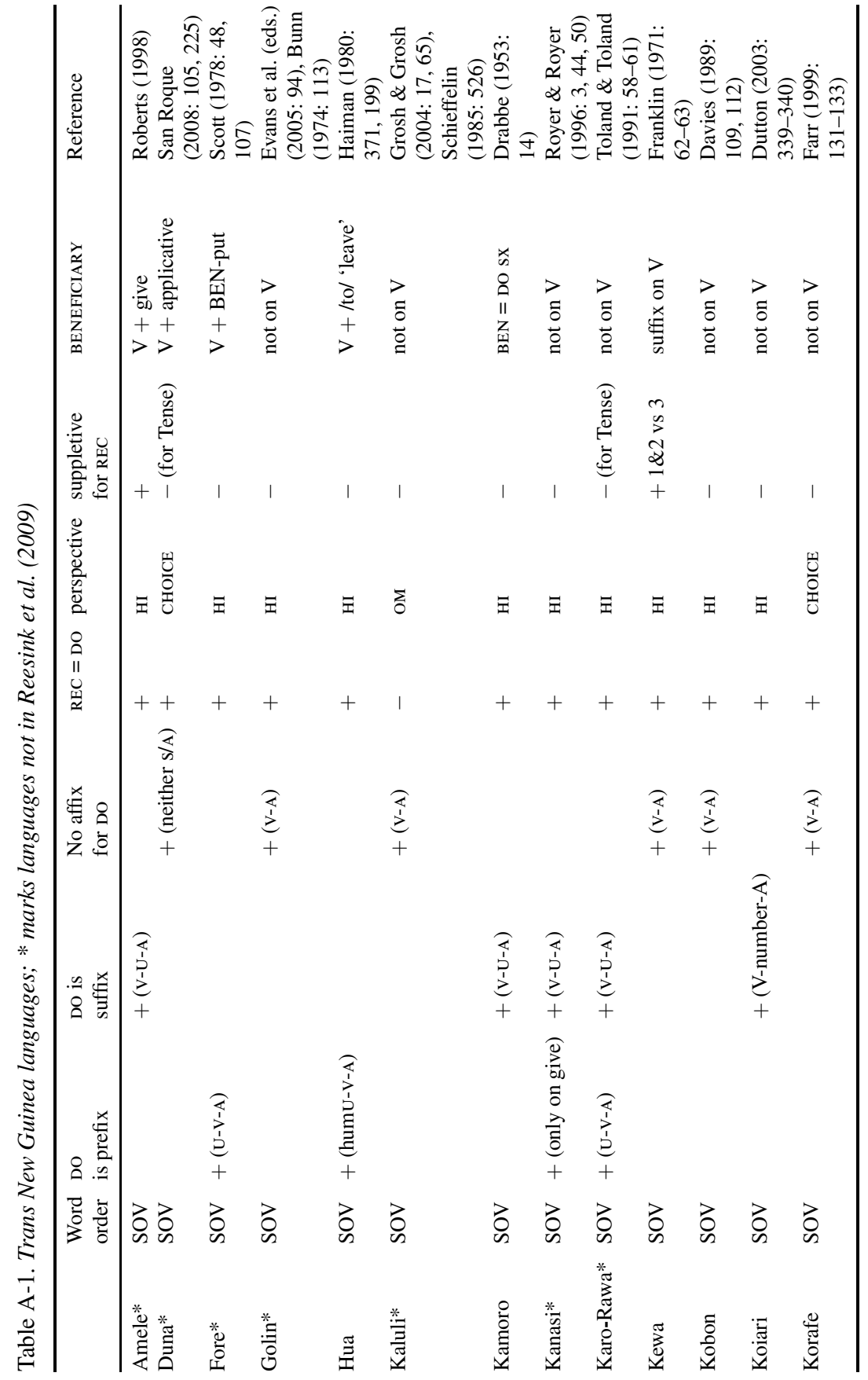




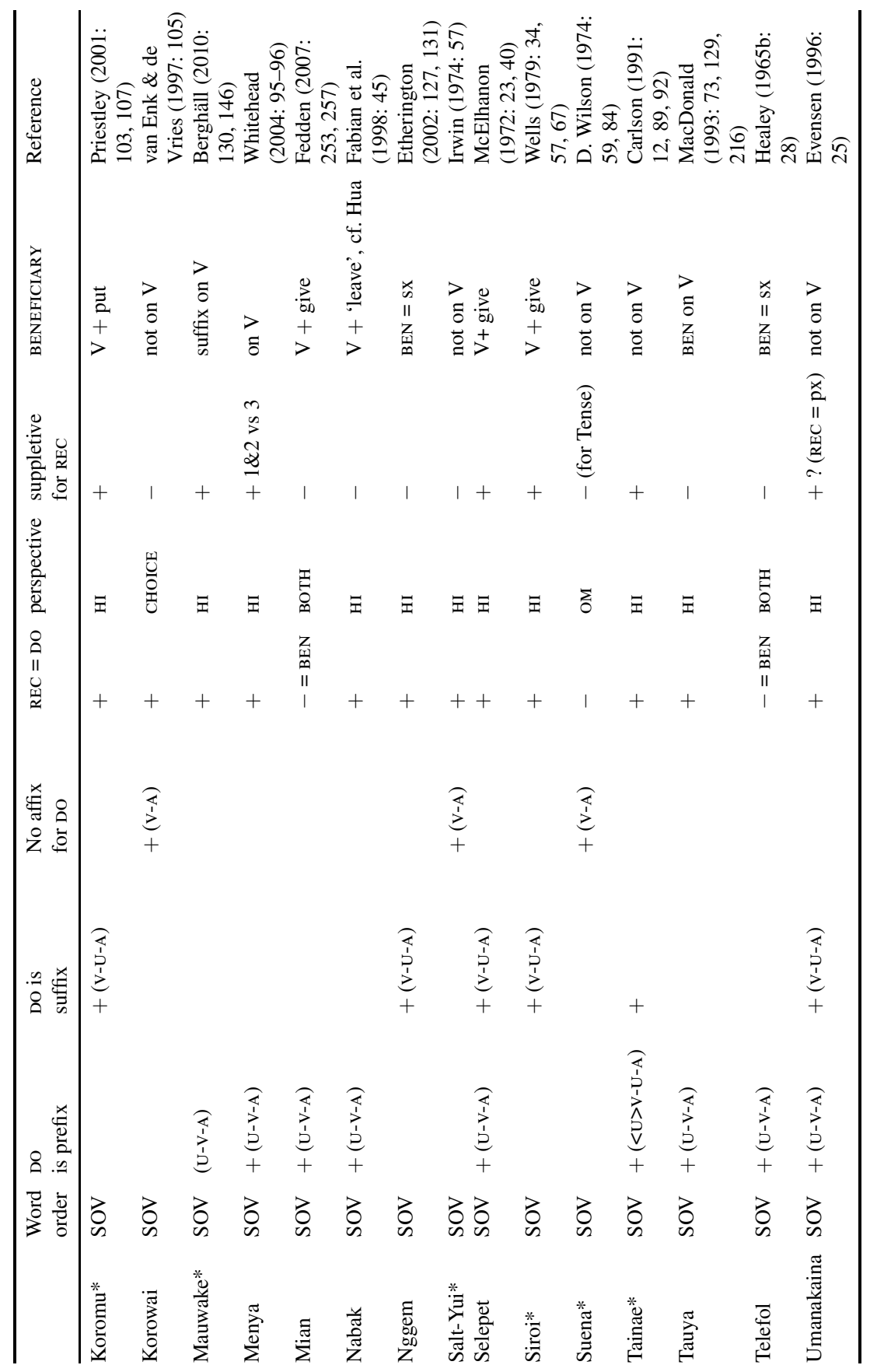




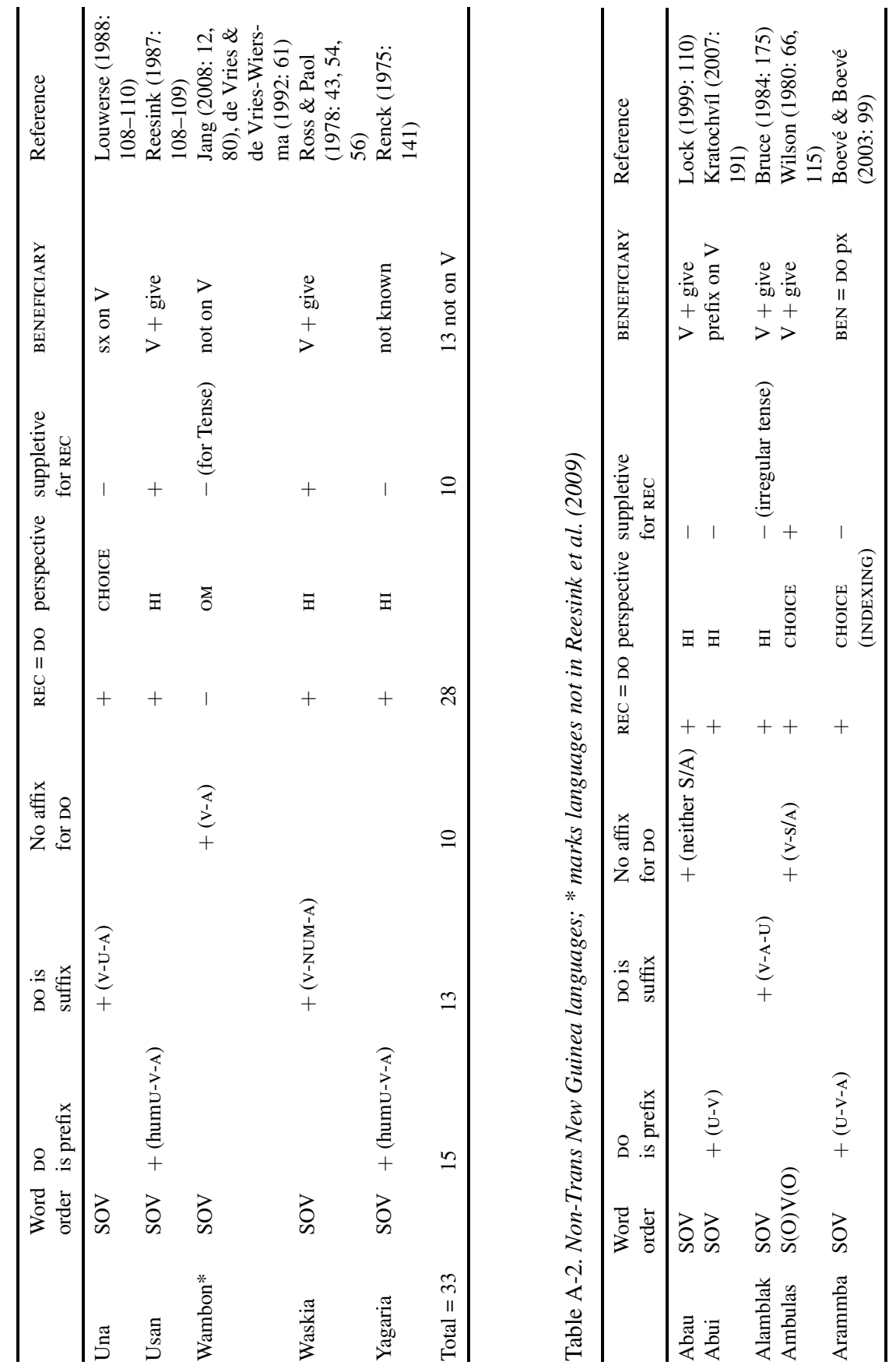




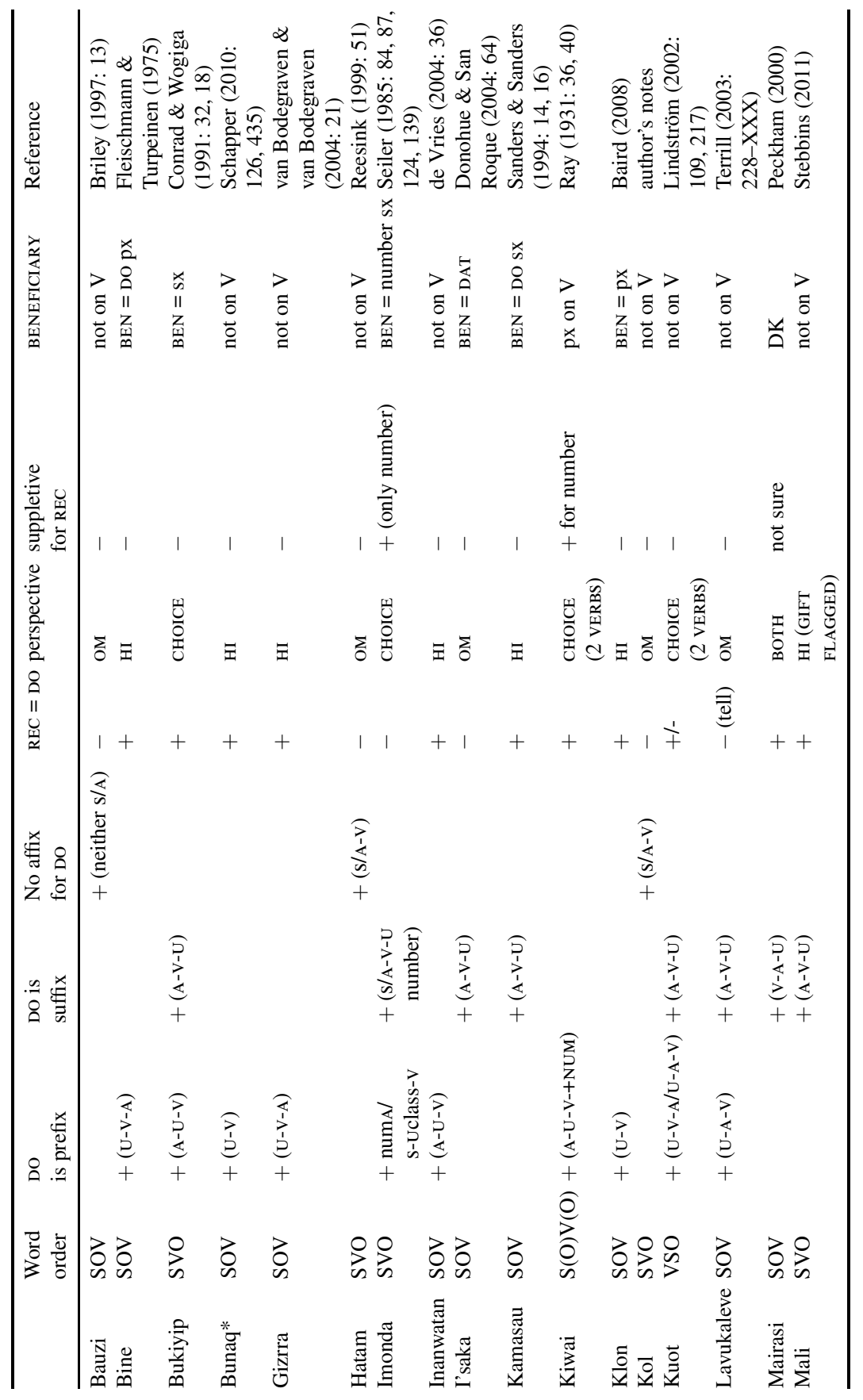




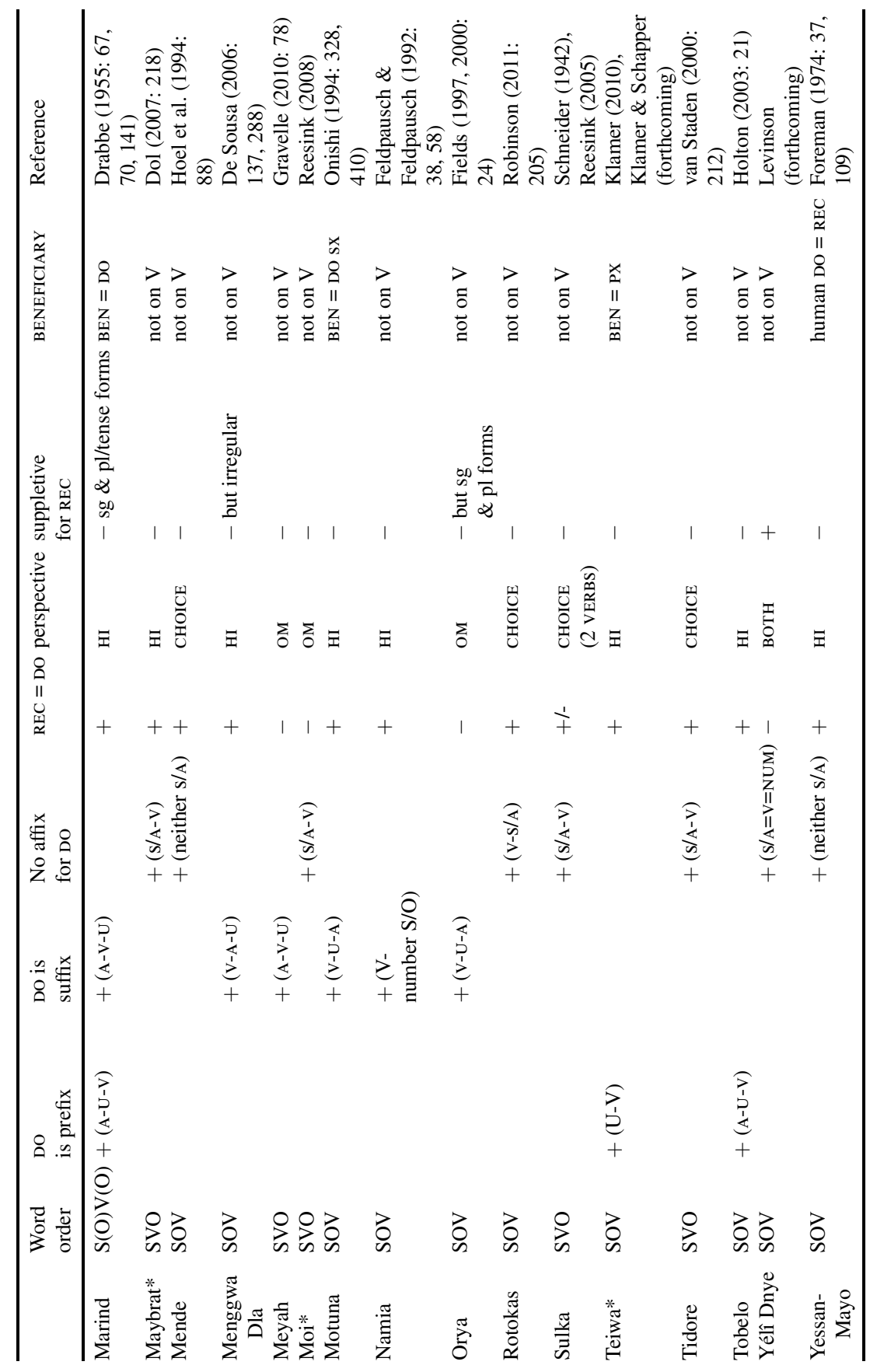




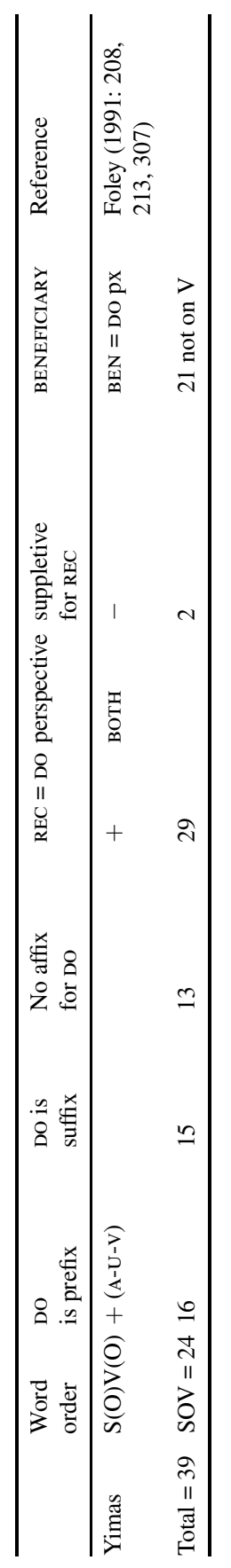




\section{Supplementary Online Materials}

http://www.degruyter.com/view/j/lity.2013.17.issue-00002/lity-2013-0010/ lity-2013-0010.xml

\section{References}

Aikhenvald, Alexandra Y. 2008. The Manambu language of East Sepik, Papua New Guinea. Oxford: Oxford University Press.

Baird, Louise. 2008. A grammar of Klon: A non-Austronesian language of Alor, Indonesia (Pacific Linguistics 596). Canberra: Australian National University.

Berghäll, Liisa. 2010. Mauwake reference grammar. Helsinki: Helsingin yliopisto doctoral dissertation.

Blansitt, Edward L. 1973. Bitransitive clauses. Working Papers on Language Universals 13. 11-26. Blansitt, Edward L. 1984. Dechticaetiative and dative. In Plank (ed.) 1984, 127-150.

Boevé, Marco \& Alma Boevé. 2003. Grammar essentials of the Arammba language. Manuscript, Ukarumpa: SIL.

Borg, Albert J. \& Bernard Comrie. 1984. Object diffuseness in Maltese. In Plank (ed.) 1984, 109126.

Briley, David. 1997. Four grammatical marking systems in Bauzi. In Karl Franklin (ed.), Papers in Papuan linguistics no. 2 (Pacific Linguistics A-85), 1-131. Canberra: Australian National University.

Bruce, Les. 1984. The Alamblak language of Papua New Guinea (East Sepik) (Pacific Linguistics C-81). Canberra: Australian National University.

Bunn, Gordon. 1974. Golin grammar (Workpapers in Papua New Guinea Languages 5). Ukarumpa: SIL.

Carlson, Terry. 1991. Tainae grammar essentials. Manuscript, Ukarumpa: SIL. http://www.sil.org/ pacific/png/abstract.asp?id=48961

Comrie, Bernard. 2003. Recipient person suppletion in the verb 'give'. In Mary Ruth Wise, Thomas N. Headland \& Ruth Brend (eds.), Language and life, essays in memory of Kenneth L. Pike, 265-281. Dallas: SIL International and The University of Texas at Arlington.

Conrad, Robert J. with Kepas Wogiga. 1991. An outline of Bukiyip grammar (Pacific Linguistics C-113). Canberra: Australian National University.

Corbett, Greville G. 2007. Canonical typology, suppletion, and possible words. Language 83. 842.

Davies, John. 1989. Kobon (Croom Helm Descriptive Grammars). London: Croom Helm.

De Sousa, Hilario. 2006. The Menggwa Dla language of Papua New Guinea. Sydney: University of Sydney doctoral dissertation.

de Vries, Lourens \& Robinia de Vries-Wiersma. 1992. The morphology of Wambon. Leiden: KITLV Press.

de Vries, Lourens. 2004. A short grammar of Inanwatan (Pacific Linguistics 560). Canberra: Australian National University.

Dol, Philomena. 2007. A grammar of Maybrat, a language of the Bird's Head peninsula, Papua Province, Indonesia (Pacific Linguistics 586). Canberra: Australian National University.

Donohue, Mark \& Lila San Roque. 2004. I'saka, a sketch grammar of a language of North-Central New Guinea (Pacific Linguistics 554). Canberra: Australian National University.

Drabbe, Peter. 1953. Spraakkunst van de Kamoro-taal. Den Haag: Nijhoff.

Drabbe, Peter. 1955. Spraakkunst van het Marind (Studia Instituti Anthropos 2). Wien-Mödling: Missiehuis St. Gabriel.

Dryer, Matthew S. 1986. Primary objects, secondary objects, and antidative. Language 62. 808845. 
Dutton, Tom. 2003. A dictionary of Koiari, Papua New Guinea, with grammar notes (Pacific Linguistics 534). Canberra: Australian National University.

Etherington, Paul. 2002. Nggem morphology and syntax. Darwin: Northern Territory University MA thesis.

Evans, Nicholas, Jutta Besold, Hywel Stoakes \& Alan Lee (eds.). 2005. Materials on Golin. Melbourne: Department of Linguistics, University of Melbourne.

Evans, Nicholas \& Stephen C. Levinson. 2009. The myth of language universals: Language diversity and its importance for cognitive science. Behavioral and Brain Sciences 32. 429-492.

Evensen, Sigmund. 1996. Umanakaina grammar, from morpheme to discourse. Manuscript, Ukarumpa: SIL.

Fabian, Grace, Edmund Fabian \& Bruce Waters.1998. Morphology, syntax and cohesion in Nabak, Papua New Guinea (Pacific Linguistics C-144). Canberra: Australian National University.

Farr, Cynthia J. M. 1999. The interface between syntax and discourse in Korafe, a Papuan language of Papua New Guinea (Pacific Linguistics C-148). Canberra: Australian National University.

Fedden, Sebastian. 2007. A grammar of Mian, a Papuan language of New Guinea. Melbourne: University of Melbourne doctoral dissertation.

Fedden, Sebastian. 2010. Ditransitives in Mian. In Andrej Malchukov, Martin Haspelmath \& Bernard Comrie (eds.), Studies in ditransitive constructions: A comparative handbook, 456485. Berlin: De Gruyter Mouton.

Feldpausch, Tom \& Becky Feldpausch. 1992. Namia grammar essentials. In John R. Roberts (ed.), Namia and Amanab grammar essentials (Data Papers on Papua New Guinea Languages 39), 3-97. Ukarumpa: SIL.

Fields, Philip C. 1997. Pivot and nominalisation in Orya. In Karl Franklin (ed.), Papers in Papuan linguistics no. 2 (Pacific Linguistics A-85), 237-269. Canberra: Australian National University.

Fields, Philip C. 2000. A summary of Orya grammar. Manuscript, SIL Indonesia.

Fleischmann, Lillian \& Sinikka Turpeinen. 1975. Bine grammar essentials. Manuscript, Ukarumpa: SIL.

Foley, William A. 1986. The Papuan languages of New Guinea. Cambridge: Cambridge University Press.

Foley, William A. 1991. The Yimas language of New Guinea. Stanford, CA: Stanford University Press.

Foley, William A. 1997. Anthropological linguistics. Oxford: Blackwell.

Foley, William A. 2000. The languages of New Guinea. Annual Review of Anthropology 29. 357404.

Foley, William A. 2005. Linguistic prehistory in the Sepik-Ramu basin. In Pawley et al. (eds.) 2005, 109-144.

Foreman, Velma. 1974. Grammar of Yessan-Mayo (Language Data, Asian-Pacific Series 4). Santa Ana: SIL.

Franklin, Karl J. 1971. A grammar of Kewa, New Guinea (Pacific Linguistics C-16). Canberra: Australian National University.

Gleitman, Lila. 1990. The structural sources of verb meanings. Language Acquisition 1. 3-55.

Gravelle, Gilles. 2010. Meyah, a language of West Papua, Indonesia (Pacific Linguistics 619). Canberra: Australian National University.

Grosh, Andrew \& Sylvia Grosh. 2004. Grammar essentials for the Kaluli language. Manuscript, Ukarumpa: SIL. http://www.sil.org/pacific/png/abstract.asp?id=51986

Haiman, John. 1980. Hua: A Papuan language of the Eastern Highlands of New Guinea. Amsterdam: Benjamins.

Haspelmath, Martin. 2005. Argument marking in ditransitive alignment types. Linguistic Discovery 3(1). 1-21.

Haspelmath, Martin. 2011. Ditransitive constructions: The verb 'give'. In Matthew S. Dryer \& Martin Haspelmath (eds.), The world atlas of language structures online, Chapter 105. 
München: Max Planck Digital Library. http://wals.info/chapter/105 (accessed on 28 December 2012)

Healey, Alan. 1964. A survey of the Ok family of languages. Canberra: Australian National University doctoral dissertation.

Healey, Phyllis M. 1965. Telefol verb phrases. Pacific Linguistics A-5, 27-53. Canberra: Australian National University.

Healey, Phyllis M. 1965. Telefol clause structure. Pacific Linguistics A-5, 1--26. Canberra: Australian National University.

Hepner, Mark. 2006. Bargam grammar sketch. Manuscript, Ukarumpa: SIL. http://www.sil.org/ pacific/png/abstract.asp?id $=49645$

Hoel, Hanna Marie, Tarja Ikäheimonen \& Michiyo Nozawa. 1994. Mende grammar essentials. Manuscript, Ukarumpa: SIL. http://www.sil.org/pacific/png/abstract.asp?id=48482

Holton, Gary. 2003. Tobelo. München: Lincom.

Hyman, Larry M. \& Alessandro Duranti. 1982. On the object relation in Bantu. In Paul J. Hopper \& Sandra A. Thompson (ed.), Studies in transitivity (Syntax and Semantics 15), 217-239. New York: Academic Press.

Irwin, Barry. 1974. Salt-Yui grammar (Pacific Linguistics B-35). Canberra: Australian National University.

Jang, Hong-Tae. 2008. Morphology and syntax of Wambon. Manuscript, SIL Indonesia.

Klamer, Marian. 2010. A grammar of Teiwa. Berlin: De Gruyter Mouton.

Klamer, Marian \& Antoinette Schapper (forthcoming). The development of 'give' constructions in the Papuan languages of Timor-Alor-Pantar.

Kratochvíl, František 2007. A grammar of Abui. Leiden: Universiteit Leiden doctoral dissertation.

Levinson, Stephen C. (forthcoming). A grammar of Yélì Dnye, the Papuan language of Rossel Island.

Lindström, Eva. 2002. Topics in the grammar of Kuot, a non-Austronesian language of New Ireland, Papua New Guinea. Stockholm: Stockholms universitet doctoral dissertation.

Lock, Arjen. 2011. Abau grammar (Data Papers on Papua New Guinea Languages 57). Ukarumpa: SIL-PNG Academic Publications.

Louwerse, Jan. 1988. The morphosyntax of Una in relation to discourse structure (Pacific Linguistics B-100). Canberra: Australian National University.

MacDonald, Lorna. 1990. A grammar of Tauya. Berlin: Mouton de Gruyter.

Margetts, Anna. 2008. Learning verbs without boots and straps? The problem of 'give' in Saliba. In Melissa Bowerman \& Penelope Brown (eds.), Crosslinguistic perspectives on argument structure, 111-137. New York: Erlbaum.

McElhanon, Kenneth A. 1972. Selepet grammar, Part I, From root to phrase (Pacific Linguistics B-21). Canberra: Australian National University.

McElhanon, Kenneth A. 1973. Towards a typology of the Finisterre-Huon languages, New Guinea (Pacific Linguistics B-22). Canberra: Australian National University.

McElhanon, Kenneth A. \& Clemens L. Voorhoeve. 1970. The Trans-New Guinea phylum: Explorations in deep-level genetic relationships (Pacific Linguistics B-16). Canberra: Australian National University.

Mosel, Ulrike. 1984. Tolai syntax and its historical development (Pacific Linguistics B-92). Canberra: Australian National University.

Newman, John. 1996. Give: A cognitive linguistic study (Cognitive Linguistics Research 7). Berlin: Mouton de Gruyter.

Newman, John. 2002. Culture, cognition, and the grammar of 'give' clauses. In N. J. Enfield (ed.), Ethnosyntax: Explorations in grammar and culture, 74-95. Oxford: Oxford University Press.

Newman, John (ed.). 1998. The linguistics of giving. Amsterdam: Benjamins.

Odé, Cecilia. 2002. A sketch of Mpur. In Reesink (ed.) 2002, 45-107.

Onishi, Masayuki. 1994. A grammar of Motuna (Bougainville, Papua New Guinea). Canberra: Australian National University doctoral dissertation. 
Pawley, Andrew. 2005. The chequered career of the Trans New Guinea hypothesis: Recent research and its implications. In Pawley et al. (eds.) 2005, 67-107.

Pawley, Andrew. 2007. Recent research on the historical relationships of the Papuan languages, or: What does linguistics say about the prehistory of Melanesia. In Jonathan Scott Friedlaender (ed.), Genes, language, and culture history in the Southwest Pacific, 36-58. Oxford: Oxford University Press.

Pawley, Andrew, Robert Attenborough, Jack Golson \& Robin Hide (eds.). 2005. Papuan pasts: Cultural, linguistic and biological histories of Papuan-speaking peoples (Pacific Linguistics 572). Canberra: Australian National University.

Peckham, Lloyd. 2000. Tentative Mairasi grammar. Manuscript, SIL Indonesia.

Pinker, Steven. 1989. Learnability and cognition: The acquisition of argument structure. Cambridge, MA: MIT Press.

Plank, Frans (ed.).1984. Objects: Towards a theory of grammatical relations. London: Academic Press.

Priestley, Carol. 2001. The morphosyntax of verbs in Koromu (Kesawai), a language of Papua New Guinea. Canberra: Australian National University MA thesis.

Ray, S. H. 1931. A grammar of the Kiwai language, Fly Delta, Papua, with a Kiwai vocabulary, by Rev. E. Baxter Riley. Port Moresby: Edward George Baker, Government Printer.

Reesink, Ger. 1987. Structures and their functions in Usan. Amsterdam: Benjamins.

Reesink, Ger. 1999. A grammar of Hatam, Bird's head Peninsula, Irian Jaya (Pacific Linguistics C-146). Canberra: Australian National University.

Reesink, Ger. 2005. Sulka of East New Britain, a mixture of Oceanic and Papuan traits. Oceanic Linguistics 44. 145-193.

Reesink, Ger. 2008. Lexicon and syntax from an emic viewpoint. Studies in Language 32. 866893.

Reesink, Ger, Ruth Singer \& Michael Dunn. 2009. Explaining the linguistic diversity of Sahul using population models. PLoS Biology 7(11). e1000241. http://www.plosbiology.org/article/ info\%3Adoi\%2F10.1371\%2Fjournal.pbio. 1000241

Reesink, Ger (ed.). 2002. Languages of the Eastern Bird's Head (Pacific Linguistics 524). Canberra: Australian National University.

Renck, Günther L. 1975. A grammar of Yagaria (Pacific Linguistics B-40). Canberra: Australian National University.

Roberts, John. 1998. Give in Amele. In Newman (ed.) 1998, 1-33.

Robinson, Stuart. 2011. Split intranstivity in the Rotokas language of Bougainville. Nijmegen: Radboud Universiteit doctoral dissertation.

Ross, Malcolm with John Natu Paol. 1978. A Waskia grammar sketch and vocabulary (Pacific Linguistics B-56). Canberra: Australian National University.

Ross, Malcolm. 2000. Pronouns and Papuan languages. Pre-publication manuscript.

Ross, Malcolm. 2005. Pronouns as a preliminary diagnostic for grouping Papuan languages. In Pawley et al. (eds.) 2005, 15-65.

Rowe, Karen. 2005. Siar-Lak grammar essentials (Data Papers on Papua New Guinea Languages 50). Ukarumpa: SIL

Royer, Gottlieb \& Margarita Royer. 1990. Grammar essentials for Kanasi. Manuscript, Ukarumpa: SIL.

Sanders, Arden \& Joy Sanders. 1994. Kamasau (Wand Tuan) grammar: Morpheme to sentence. Manuscript, Ukarumpa: SIL. http://www.sil.org/pacific/png/abstract.asp?id=47683

San Roque, Lila. 2008. An introduction to Duna grammar. Canberra: Australian National University doctoral dissertation.

Schapper, Antoinette. 2010. Bunaq: A Papuan language of central Timor. Canberra: Australian National University doctoral dissertation.

Schieffelin, Bambi. 1985. The acquisition of Kaluli. In Dan Isaac Slobin (ed.), The crosslinguistic study of language acquisition, Vol. 1: The data, 525-593. Hillsdale, NJ: Erlbaum. 
Schneider, Joseph. 1942. Grammatik der Sulka-Sprache. Manuscript, Kokopo. Microfilm edn. (Micro-bibliotheca Anthropos 36), Posieux, Switzerland: Anthropos-Institut, 1962.

Scott, Graham. 1978. The Fore language of Papua New Guinea (Pacific Linguistics B-47). Canberra: Australian National University.

Seiler, Walter. 1985. Imonda, a Papuan language (Pacific Linguistics B-93). Canberra: Australian National University.

Smith, Jean 1977. Mianmin sentence structure. In Richard Loving (ed.), Workpapers in Papua New Guinea Languages, Vol. 22, 5-53. Ukarumpa: Summer Institute of Linguistics.

Smith, Jean \& Pam Weston. 1974. Notes on Mianmin grammar. In Richard Loving (ed.), Workpapers in Papua New Guinea Languages: Studies in Languages of the Ok Family, Vol. 7, 35-142. Ukarumpa, PNG: Summer Institute of Linguistics.

Stebbins, Tonya. 2011. Mali (Baining) grammar (Pacific Linguistics 623). Canberra: Australian National University.

Terrill, Angela. 2003. A grammar of Lavukaleve. Berlin: Mouton de Gruyter.

Toland, Norma R. \& Donald F. Toland. 1991. Reference grammar of the Karo/Rawa language (Data Papers on Papua New Guinea Languages 38). Ukarumpa: SIL.

Tuggy, David. 1998. Giving in Nahuatl. In Newman (ed.) 1998, 35-65.

van Bodegraven, Nico \& Elly van Bodegraven. 2004. Gizrra grammar essentials. Manuscript, Ukarumpa: SIL.

van Enk, Gerrit J. \& Lourens de Vries. 1997. The Korowai of Irian Jaya. Oxford: Oxford University Press.

van Staden, Miriam. 2000. Tidore: A linguistic description of a language of the North Moluccas. Leiden: Universiteit Leiden doctoral dissertation.

Wells, Margaret A. 1979. Siroi grammar (Pacific Linguistics B-51). Canberra: Australian National University.

Whitehead, Carl. 2004. A reference grammar of Menya, an Angan language of Papua New Guinea. Winnipeg: University of Manitoba doctoral dissertation.

Wilson, Darryl. 1974. Suena grammar (Workpapers in Papua New Guinea Languages 8). Ukarumpa: SIL

Wilson, Patricia R. 1980. Ambulas grammar (Workpapers in Papua New Guinea Languages 26). Ukarumpa: SIL.

Wurm, Stephen A. (ed.). 1975. New Guinea area languages and language study, Vol. 1: Papuan languages and the New Guinea linguistic scene (Pacific Linguistics C-38). Canberra: Australian National University.

Z'graggen, John A. 1980. A comparative word list of the Northern Adelbert Range languages, Madang Province, Papua New Guinea (Pacific Linguistics D-31). Canberra: Australian National University. 